Article

\title{
Methanol Synthesis: Optimal Solution for a Better Efficiency of the Process
}

\author{
Grazia Leonzio \\ Department of Industrial and Information Engineering and Economics, University of L'Aquila, \\ Via Giovanni Gronchi 18, 67100 L'Aquila, Italy; grazia.leonzio@graduate.univaq.it; Tel.: +39-3401537804
}

Received: 31 January 2018; Accepted: 16 February 2018; Published: 25 February 2018

\begin{abstract}
In this research, an ANOVA analysis and a response surface methodology are applied to analyze the equilibrium of methanol reaction from pure carbon dioxide and hydrogen. In the ANOVA analysis, carbon monoxide composition in the feed, reaction temperature, recycle and water removal through a zeolite membrane are the analyzed factors. Carbon conversion, methanol yield, methanol productivity and methanol selectivity are the analyzed responses. Results show that main factors have the same effect on responses and a common significant interaction is not present. Carbon monoxide composition and water removal have a positive effect, while temperature and recycle have a negative effect on the system. From central composite design, an optimal solution is found in order to overcome thermodynamic limit: the reactor works with a membrane at lower temperature with carbon monoxide composition in the feed equal to $10 \mathrm{~mol} \%$ and without recycle. In these conditions, carbon conversion, methanol yield, methanol selectivity, and methanol production are, respectively, higher than $60 \%$, higher than $60 \%$, between $90 \%$ and $95 \%$ and higher than $0.15 \mathrm{~mol} / \mathrm{h}$ when considering a feed flow rate of $1 \mathrm{~mol} / \mathrm{h}$. A comparison with a traditional reactor is also developed: the membrane reactor ensures to have a carbon conversion higher of the $29 \%$ and a methanol yield higher of the $34 \%$. Future researches should evaluate an economic analysis about the optimal solution.
\end{abstract}

Keywords: methanol reaction; equilibrium reactions; ANOVA analysis; response surface methodology; optimization

\section{Introduction}

Methanol production via $\mathrm{CO}_{2}$ hydrogenation is an important representative among the chemical conversions of $\mathrm{CO}_{2}$ and offers challenging opportunities for sustainable development.

As a raw material, methanol constitutes the basis for the production of hundreds of chemicals, such as formaldehyde, methyl tertbutyl ether (MTBE), acetic acid, methyl methacrylate, dimethyl terephthalate, and olefins (ethylene and propylene), all basic chemical building blocks for a number of common products [1]. Methanol can also be used as transportation fuel, as a fuel cell hydrogen carrier, as well as in wastewater treatment or in electricity production. It is then an excellent fuel and a key starting material of important industrial reactions [2]. In the recent years, also, methanol is suggested as alternative for chemical energy carrier [3,4].

Generally, in industrial applications, methanol can be produced from syngas, a mixture of $\mathrm{CO}$, $\mathrm{CO}_{2}$ and $\mathrm{H}_{2}$ at $50-100$ bar and $250{ }^{\circ} \mathrm{C}-300{ }^{\circ} \mathrm{C}$, using copper and zinc-based catalyst $[5,6]$. These catalysts are already active at $200{ }^{\circ} \mathrm{C}$ and selective towards the formation of $\mathrm{H}_{2}$ and $\mathrm{CO}_{2}$. Alternative routes and its use as fuel and chemical are the core of methanol economy [4,7]. Pontzen et al. [8] experimentally show that methanol can be produced from $\mathrm{CO}_{2}$ and $\mathrm{H}_{2}$ using conventional catalysts as $\mathrm{CuO} / \mathrm{Al}_{2} \mathrm{O}_{3} / \mathrm{ZnO}$. However, studies show that the equilibrium yield of methanol from $\mathrm{CO}_{2}$ at $200{ }^{\circ} \mathrm{C}$ and 50 bar is slightly less than $40 \%$, whereas the yield from a mixture of $\mathrm{CO}_{2}$ and $\mathrm{CO}$ at the same conditions is greater than $80 \%$ [9]. 
The production of methanol from pure $\mathrm{CO}_{2}$ and $\mathrm{H}_{2}$ has also some thermodynamic limits, as shown by Zachopoulos and Heracleous [10], suggesting the removal of water through sorbents. In fact, water inhibits the reaction rate of methanol formation via $\mathrm{CO}_{2}$ hydrogenation [11]. In particular, water produced from reverse water gas shift greatly reduces the methanol synthesis rate by suppressing the reaction of methanol production.

Works related to these considerations are few in literature. In fact, works about the production of methanol by syngas are mainly present and different strategies are proposed to improve the efficiency of the process. Mainly, studies involve the in situ methanol removal. Examples are methanol adsorption on fine alumina powder or the use of a solvent, such as tetraethylene glycol, n-butanol, or n-hexane [12]. Westerterp et al. [13] suggest the selective adsorption of water and methanol on a solid, in a trickle bed reactor. An alternative method is based on the in situ separation of reaction products by condensing them on the surface of a condenser inside the reactor, close to the catalyst bed [14]. These solutions have some disadvantages due to the introduction of other chemicals, complicated operations and low space time yields. An alternative to overcome chemical equilibrium is the in-situ condensation of methanol without additional adsorbents or coolers. Van Bennekom et al. [15] suggest the condensation of methanol in situ at high pressure (200 bar) and low temperature $\left(200^{\circ} \mathrm{C}\right)$. It is evident that thermodynamic barrier can be eliminated by removal of reaction products based on the principle of Le Chatelier. Gallucci and Basile [16] suggest the recycle of unconverted synthesis gas after product separation by condensation or the water removal using selective, permeable membranes. The first membrane reactor for methanol production is used by Struis et al. [17] using lithiated Nafion membrane at $200{ }^{\circ} \mathrm{C}$ and 4.3 bar. In another work of Struis and Stucki [18] a modeling of membrane reactor for methanol reaction is developed, using a Nafion membrane: a single pass yield is improved by $40 \%$. However, this application is limited because the operative temperature of Nafion membrane is lower than $200^{\circ} \mathrm{C}$. Chen and Yuan [19] analyze a one-dimensional isothermal pseudo-homogeneous model for membrane reactor producing methanol. A silicone rubber/ceramic composite membrane is used. Results show that conversion in membrane reactor is increased by $22 \%$ when compared to traditional fixed bed reactor. Also, Barbieri et al. [20] use a ceramic membrane for a reactor producing methanol. Gallucci et al. [21] analyze a zeolite membrane reactor: at the same conditions, conversions are higher in membrane reactor respect to traditional reactor. In other words, the same conversions can be obtained in membrane reactor with lower temperature and pressure compared to the traditional reactor. This aspect should notably reduce the energy demand. A mathematical model for zeolite membrane reactor permeable to water is developed by Gallucci and Basile [16]. Results shows that it is possible to have s higher conversion and methanol selectivity with respect to a traditional reactor at the same operating experimental conditions.

When considering the analyzed works reported in literature where syngas is used in the feed, the feasibility of methanol synthesis from $\mathrm{CO}_{2}$ can be achieved by circumventing the thermodynamic limits through innovative solutions: the presence of $\mathrm{CO}$, the operation at lower temperature, the recycle of unconverted gas, the presence of membrane permeable to water inside the reactor. In fact, a mixture of $\mathrm{CO}-\mathrm{CO}_{2}$ allows for having a higher conversion and yield, as shown by Kunkes and Behrens [22]. Several studies show that a maximum in methanol production from a mixture of $\mathrm{CO}-\mathrm{CO}_{2}$ occurs at $\mathrm{CO}_{2}$ concentration of $2-5 \mathrm{~mol} \%$ of total carbon [23-25]. Lower temperatures are preferred by thermodynamic even if kinetic is not favored and a more active catalyst should be developed. The recycle of unconverted gas to ensure a higher conversion is also suggested by Montebelli et al. [26]. However, this results in high investment and operating costs and large pressure drops. The extraction of water, an inhibitor for reaction, through membrane shifts the equilibrium toward to product, but requires higher capital investment [27].

In this research, an analysis of chemical equilibrium for methanol production by pure $\mathrm{CO}_{2}$ and $\mathrm{H}_{2}$ is carried out: the above proposed solutions, as the presence of $\mathrm{CO}$ in the feed considering that the maximum methanol production is obtained with $5 \mathrm{~mol} \%$ of $\mathrm{CO}_{2}$, lower operating temperature, the recycle of unconverted gas, and the presence of zeolite membrane permeable only to water, 
are analyzed. An ANOVA analysis and a response surface methodology (RSM) through a central composite design (CCD) are developed to find the optimal solution that overcome thermodynamic limits ensuring a higher carbon conversion, methanol yield, methanol production and methanol selectivity. Data for these analyses are obtained by simulations of methanol reactor in Aspen Plus.

\section{Materials and Method}

\subsection{ANOVA Modeling}

For the methanol reactor, the estimation of main and interaction effects is developed by ANOVA analysis (analysis of variance); in this analysis, it is determined if effects and interactions among investigated factors are significant respect to experimental error $\left(\sigma_{\varepsilon}\right)$. Main factors are evaluated by Yates's algorithm through Excel 2016 software. Statistical significance is checked by F-value (Fischer variation ratio) and $p$-value (significant probability value). Model terms are selected or rejected based on probability value within $95 \%$ of confidence interval (or $5 \%$ significance level). In this research, $\sigma_{\varepsilon}$ is evaluated by means of the mean square (MS) of interactions that are not significant. A $2^{4}$ full factorial design with 16 simulation tests is performed for this research [28]. A mathematical model could be obtained with significant factors and the quality of the model is assessed by the coefficient of determination, $R^{2}$. $R^{2}$ represents a pure correlation between measured and predicted values, and it is indicative of response variation explained by model. Then, in this statistic method all factor levels are fully changed so that it is possible to measure any variation in response. One of the most important advantages of this method is the limited number of experiments necessary to identify the best solution. $\mathrm{CO}$ composition in the feed, reaction temperature, the recycle of unconverted gases, and the removal of water through a zeolite membrane are considered as factors in this research. Carbon conversion, methanol yield, methanol production and methanol selectivity are considered as responses, for which mathematical models are developed.

\subsection{Response Surface Methodology}

The aim of RSM is to find the optimal operating conditions of the process or to determine a region that satisfies the operating specifications, maintaining a reduced number of experiments [29]. RMS is then used in process design and optimization.

The RSM methodology is developed using a central composite design for fitting a second order model. Generally, the CCD consists of $2^{\mathrm{k}}$ factorial tests, $2 \mathrm{k}$ stars tests and $\mathrm{n}_{\mathrm{c}}$ center point tests, where $\mathrm{k}$ is the number of studied factors in the experiment. Values at center points are used to estimate the curvature of surface plot. Star points are located at distance $\alpha$ from center point and are used to estimate the coefficient of quadratic terms. Factorial points are used to estimate the coefficient of linear terms and two-way interactions.

Experimental or simulation data are used to develop a second-order polynomial model as in the following correlation (see Equation (1)) [30]:

$$
Y=\beta_{o}+\sum_{i=1}^{k} \beta_{i} \cdot A_{i}+\sum_{i=1}^{k} \sum_{j=1}^{k} \beta_{i j} \cdot A_{i} \cdot A_{j}+\sum_{i=1}^{k} \beta_{i i} \cdot A_{i}^{2}+\varepsilon
$$

where $\beta_{\mathrm{o}}$ is intercept, $\beta_{\mathrm{i}}, \beta_{\mathrm{ij}}, \beta_{\mathrm{ii}}$ are first-order, interactive, and second-order effects, respectively, $\mathrm{i}$ and $\mathrm{j}$ represent the number of $\mathrm{k}$ factors, while $\varepsilon$ is residual error. This method is then able to evaluate interaction effects, pure quadratic effects, or third- and fourth-order effects and so on; it is the most efficient evaluation method, and it improves the quality of data. To determine the significance of each term in the equation and to estimate the goodness or fitting quality, the polynomial equation is validated by analysis of variance. A response surface plot is constructed by using the fitted model. In this research, with four factors, star points are set on the centers of each face of factorial face: the value of $\alpha$ is equal to 1 and the design is denominated as face-centered central composite design. 
It requires only three levels of each factor, and in practice it is frequently difficult to change factor levels. 31 simulations in Aspen Plus are developed: 16 factorial tests, eight star tests, and six central tests, and one replication test. Software Minitab 18 is used to carry out the CCD analysis for response surface methodology.

\subsection{Reactor Modeling}

In order to carry out ANOVA and RSM analysis a modeling of methanol reactor is developed in Aspen Plus software, as shown in Figure 1. It is an equilibrium reactor where reactions and equilibrium constants are defined and it is fed with $\mathrm{CO}_{2}$ and $\mathrm{H}_{2}$, at flow rate equal to $1 \mathrm{~mol} / \mathrm{h}$, as shown in Table 1 . Carbon dioxide and hydrogen are in stochiometric conditions.

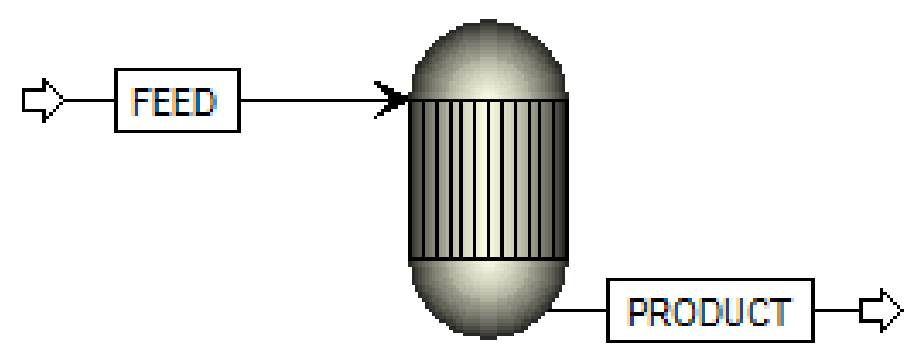

Figure 1. Equilibrium reactor for methanol production in Aspen Plus environmental.

Table 1. Material and energy balances of methanol reactor obtained in Aspen Plus environmental.

\begin{tabular}{ccc}
\hline Factor & Feed & Product \\
\hline Temperature $(\mathrm{K})$ & 493 & 493 \\
Pressure $(\mathrm{bar})$ & 55 & 55 \\
Vapor fraction & 1 & 1 \\
Total flow rate $(\mathrm{mol} / \mathrm{h})$ & 1 & 0.766 \\
$\mathrm{CO}_{2}$ flow rate $(\mathrm{mol} / \mathrm{h})$ & 0.25 & 0.165 \\
$\mathrm{H}_{2}$ flow rate $(\mathrm{mol} / \mathrm{h})$ & 0.75 & 0.51 \\
$\mathrm{H}_{2} \mathrm{O}$ flow rate $(\mathrm{mol} / \mathrm{h})$ & 0 & 0.084 \\
$\mathrm{CO}$ flow rate $(\mathrm{mol} / \mathrm{h})$ & 0 & 0.0069 \\
\hline
\end{tabular}

The reactor is characterized according the following reactions (see Equations (2) and (3)):

$$
\begin{gathered}
\mathrm{CO}_{2}+3 \mathrm{H}_{2} \leftrightarrow \mathrm{CH}_{3} \mathrm{OH}+\mathrm{H}_{2} \mathrm{O} \Delta H_{298 \mathrm{~K}}=-49.43 \mathrm{~kJ} / \mathrm{mol} \\
\mathrm{CO}_{2}+\mathrm{H}_{2} \leftrightarrow \mathrm{CO}+\mathrm{H}_{2} \mathrm{O} \Delta H_{298 \mathrm{~K}}=+41.12 \mathrm{~kJ} / \mathrm{mol}
\end{gathered}
$$

The equilibrium constants of two reactions are respectively the following (see Equations (4) and (5)) [24]:

$$
\begin{gathered}
\ln \left(\mathrm{Keq}_{1}\right)=\frac{7060}{T}-24.389 \\
\ln \left(1 / \mathrm{Keq}_{2}\right)=-\frac{4773}{T}+4.672
\end{gathered}
$$

First reaction is exothermic so equilibrium constant decreases with temperature; second reaction is endothermic so equilibrium constant increases with temperature. As shown in [24], initially $\mathrm{CO}_{2}$ reacts to give $\mathrm{CO}$ as well as methanol. Since the reverse water gas shift is endothermic, and because of decreasing $\mathrm{CO}_{2}$ concentration, this slows down the hydrogenation of $\mathrm{CO}_{2}$ at the reactor inlet. The reverse water gas shift reaches its equilibrium value and switches direction. This results in an inflection point in temperature profile and a concentration evolution of water and methanol. From this point onward, reactions are strictly in series. 
A membrane reactor is modelled using six stages in series of reactors and water separators, because the aim of this research is to analyze the equilibrium of methanol reaction by removing water. In fact, membrane is considered to be both not permeable and poorly permeable to other compounds, due to the condensation of water in membrane pores. With these considerations, the presence of membrane inside the reactor is evaluated as percentage of water removal by reaction site to permeation site, as is also suggested by Gallucci and Basile [16].

SRK thermodynamic model is used to carry out simulations in Aspen Plus, because it is the better thermodynamic model for methanol system as found by Cheng et al. [31].

\section{Results and Discussion}

\subsection{Results of ANOVA Analysis}

Table 2 shows factors (CO concentration in the feed, reaction temperature, the recycle of unconverted gas, water removal through membrane) and the values of their levels chosen for the factorial plant.

Table 2. Factors and values of their levels chosen in the factorial design of ANOVA analysis.

\begin{tabular}{cccc}
\hline \multirow{2}{*}{ Code } & \multirow{2}{*}{ Factor } & \multicolumn{2}{c}{ Level } \\
\cline { 3 - 4 } & & $\mathbf{( - )}$ & $\mathbf{( + )}$ \\
\hline $\mathrm{A}$ & CO concentration in the feed $(\mathrm{mol} \%)$ & 0 & 20 \\
$\mathrm{~B}$ & Temperature $\left({ }^{\circ} \mathrm{C}\right)$ & 200 & 280 \\
$\mathrm{C}$ & Recycle $(\%)$ & 0 & 90 \\
$\mathrm{D}$ & Water removal $(\%)$ & 0 & 80 \\
\hline
\end{tabular}

Carbon conversion to methanol, methanol yield, methanol production, and methanol selectivity are the analyzed responses. Carbon conversion, methanol yield and methanol selectivity are defined, respectively, as in the following relations (see Equations (6)-(8))

$$
\begin{gathered}
\text { Conversion }(\%)=\frac{\left(\mathrm{CO}_{2, \text { in }}+\mathrm{CO}_{\text {in }}\right)-\left(\mathrm{CO}_{2, \text { out }}+\mathrm{CO}_{\text {out }}\right)}{\left(\mathrm{CO}_{2, \text { in }}+\mathrm{CO}_{\text {in }}\right)} \\
\mathrm{MeOH} \text { yield }(\%)=\frac{\mathrm{MeOH} \text { out }}{\mathrm{CO}_{2, \text { in }}+\mathrm{CO}_{\text {in }}} \\
\mathrm{MeOH} \text { selectivity }(\%)=\frac{\mathrm{MeOH}_{\text {out }}}{\left(\mathrm{CO}_{2, \text { in }}+\mathrm{CO}_{\text {in }}\right)-\left(\mathrm{CO}_{2, \text { out }}+\mathrm{CO}_{\text {out }}\right)}
\end{gathered}
$$

Figure 2 shows the results of ANOVA analysis with significant factors and interactions, while Table 3 reports the general result of ANOVA analysis. As shown in Figure 2 carbon conversion in $\%$, methanol production in $\mathrm{mol} / \mathrm{h}$, methanol yield in $\%$, methanol selectivity in $\%$ are the chosen responses. 


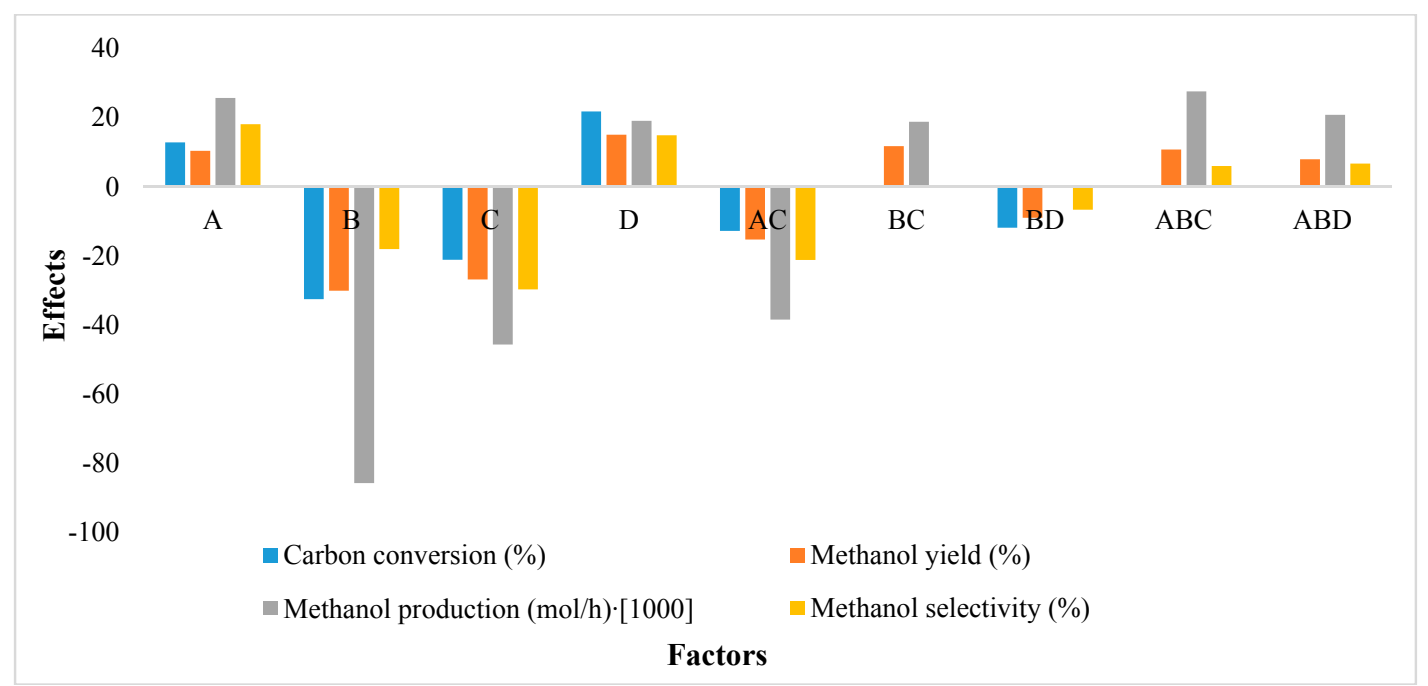

Figure 2. Results of ANOVA analysis considering only significant factors and interactions $\left(\mathrm{A}=\mathrm{CO}\right.$ concentration in the feed in mol $\%, \mathrm{~B}=\mathrm{Temperature} \mathrm{in}{ }^{\circ} \mathrm{C}$, $\mathrm{C}=$ Recycle in $\%, \mathrm{D}=$ Water removal in $\%$ ) with values of their effects.

Table 3. Results of ANOVA analysis ( $\mathrm{A}=\mathrm{CO}$ concentration in the feed in mol $\%, \mathrm{~B}=$ Temperature in ${ }^{\circ} \mathrm{C}, \mathrm{C}=$ Recycle in $\%, \mathrm{D}=\mathrm{Water}$ removal in $\%$ ).

\begin{tabular}{|c|c|c|c|c|c|c|c|c|c|c|c|c|c|c|c|c|}
\hline \multirow{2}{*}{ Factors } & \multicolumn{4}{|c|}{ Carbon Conversion (\%) } & \multicolumn{4}{|c|}{ Methanol Yield (\%) } & \multicolumn{4}{|c|}{ Methanol Production $(\mathrm{mol} / \mathrm{h})$} & \multicolumn{4}{|c|}{ Methanol Selectivity (\%) } \\
\hline & Effects & F-Ratio & $p$-Value & Remarks & Effects & F-Ratio & $p$-Value & Remarks & Effects & F-Ratio & $p$-Value & Remarks & Effects & F-Ratio & $p$-Value & Remarks \\
\hline A & 12.84 & 10.02 & 0.051 & $95 \%$ & 10.40 & 15.92 & 0.016 & $98 \%$ & 1.99 & 17.12 & 0.014 & $99 \%$ & 18.12 & 71.14 & 0.001 & $100 \%$ \\
\hline B & -32.54 & 64.32 & 0.001 & $100 \%$ & -30.07 & 133.03 & 0.000 & $100 \%$ & 16.63 & 190.85 & 0.000 & $100 \%$ & -18.01 & 70.33 & 0.001 & $100 \%$ \\
\hline $\mathrm{AB}$ & -4.71 & 1.35 & 0.310 & $69 \%$ & 1.14 & 0.19 & 0.684 & $32 \%$ & 0.02 & 0.32 & 0.603 & $40 \%$ & 3.56 & 2.74 & 0.173 & $83 \%$ \\
\hline $\mathrm{C}$ & -21.13 & 27.12 & 0.006 & $99 \%$ & -26.85 & 106.08 & 0.001 & $100 \%$ & 13.26 & 54.08 & 0.002 & $100 \%$ & -29.71 & 191.31 & 0.000 & $100 \%$ \\
\hline $\mathrm{AC}$ & -12.80 & 9.95 & 0.034 & $97 \%$ & -15.25 & 34.22 & 0.004 & $100 \%$ & 4.28 & 38.28 & 0.003 & $100 \%$ & -21.17 & 97.12 & 0.001 & $100 \%$ \\
\hline $\mathrm{BC}$ & 9.34 & 5.30 & 0.083 & $92 \%$ & 11.78 & 20.44 & 0.011 & $99 \%$ & 2.55 & 9.19 & 0.039 & $96 \%$ & 5.74 & 7.14 & 0.056 & $94 \%$ \\
\hline $\mathrm{ABC}$ & 4.77 & 1.38 & 0.305 & $69 \%$ & 10.79 & 17.14 & 0.014 & $99 \%$ & 2.14 & 19.78 & 0.011 & $99 \%$ & 6.03 & 7.88 & 0.048 & $95 \%$ \\
\hline $\mathrm{D}$ & 21.83 & 28.96 & 0.006 & $99 \%$ & 15.10 & 33.55 & 0.004 & $100 \%$ & 4.19 & 9.43 & 0.037 & $96 \%$ & 14.89 & 48.06 & 0.002 & $100 \%$ \\
\hline $\mathrm{AD}$ & -3.93 & 0.94 & 0.387 & $61 \%$ & -6.32 & 5.87 & 0.072 & $93 \%$ & 0.73 & 6.37 & 0.065 & $93 \%$ & -3.90 & 3.30 & 0.144 & $86 \%$ \\
\hline $\mathrm{BD}$ & -11.87 & 8.56 & 0.043 & $96 \%$ & -8.99 & 11.89 & 0.026 & $97 \%$ & 1.49 & 4.30 & 0.107 & $89 \%$ & -6.62 & 9.51 & 0.037 & $96 \%$ \\
\hline $\mathrm{ABD}$ & 1.89 & 0.22 & 0.665 & $33 \%$ & 7.94 & 9.28 & 0.038 & $96 \%$ & 1.16 & 11.24 & 0.028 & $97 \%$ & 6.70 & 9.73 & 0.036 & $96 \%$ \\
\hline $\mathrm{CD}$ & 10.67 & 6.92 & 0.058 & $94 \%$ & 3.95 & 2.30 & 0.204 & $80 \%$ & 0.29 & 2.01 & 0.229 & $77 \%$ & 1.15 & 0.29 & 0.621 & $38 \%$ \\
\hline $\mathrm{ACD}$ & 3.75 & 0.85 & 0.408 & $59 \%$ & 1.53 & 0.35 & 0.588 & $41 \%$ & 0.04 & 0.40 & 0.559 & $44 \%$ & 0.90 & 0.17 & 0.698 & $30 \%$ \\
\hline $\mathrm{BCD}$ & -6.19 & 2.33 & 0.202 & $80 \%$ & -3.44 & 1.74 & 0.258 & $74 \%$ & 0.22 & 0.03 & 0.880 & $12 \%$ & -2.75 & 1.64 & 0.269 & $73 \%$ \\
\hline$A B C D$ & -1.91 & 0.22 & 0.663 & $34 \%$ & 4.09 & 2.46 & 0.192 & $81 \%$ & 0.31 & 3.25 & 0.146 & $85 \%$ & 2.96 & 1.90 & 0.241 & $76 \%$ \\
\hline
\end{tabular}


Results show that significant factors and interactions have the same effect on the analyzed responses.

The effect indicates how the analyzed responses vary by changing the level of factor. In other words, the effect is the effect of an independent variable on a dependent variable averaging across the levels of any other independent variables. If by increasing the level of factor, the analyzed response increases the effect is positive; if by increasing the level of factor the analyzed response decreases the effect is negative.

In this study, all the main factors are significant. $\mathrm{CO}$ concentration and water removal through a membrane have a positive effect on all responses, while temperature and the recycle of unconverted gases have a negative effect on the studied responses. In order to improve the efficiency of the process with a higher methanol production, it is better to operate in presence of $\mathrm{CO}$ or with a membrane permeable to water or with a lower temperature or without the recycle of unconverted gas, allowing to have a reactor with lower sizes and more compact.

The positive effect of $\mathrm{CO}$ in the feed is reported by Van den Bussche and Froment [24], funding an optimal $\mathrm{CO}_{2}$ composition in the feed. The positive effect of water removal is also found by Zachopoulos and Heracleous [10], using water sorption system. The negative effect of temperature is also reported by Skrzypek et al. [32]. The negative effect of recycle is due to the decreasing of kinetic. At fixed number of tubes, recycle has a negative effect: with a higher flow rate, superficial velocity increases and kinetic decreases producing a lower methanol [33]. Manenti et al. [34] suggest that conversion increases when the inlet flowrate is lowered, thanks to the increase in residence time. In fact, a lower volume of gas causes high residence times in the reactor and reaction is near to chemical equilibrium. For these reasons, stages of adiabatic reactors with intermedia refrigeration are also used.

Reaction temperature has a higher effect on carbon conversion, methanol yield and methanol production as compared to other significant factors and interactions. Recycling, instead, has a higher effect on methanol selectivity respect to other significant factors and interactions. These results suggest that temperature has an important role on equilibrium reaction. A higher efficiency of reaction is obtained operating at lower temperature, so new kind of catalysts need to be developed to operate at lower temperature.

Interaction $A C$ has a negative effect: the effect of factor $C$ is lower negative with factor $A$. The presence of $\mathrm{CO}$ and the recycle of produced gas determines a lower efficiency. Interaction $\mathrm{BC}$ has a positive effect on methanol production and methanol yield. It is possible to operate at a higher temperature using the recycle of produced gas in order to have a good efficiency of the process. However, the effect of this interaction is lower compared to the effect of main factors. Also, this interaction is not significant for carbon conversion and methanol selectivity.

Interaction $\mathrm{BD}$ has a negative effect on carbon conversion, methanol yield and methanol selectivity: the positive effect of membrane, factor $\mathrm{D}$, becomes negative at a higher temperature, factor $\mathrm{B}$. Also, in the presence of membrane, temperature must to be lower. Interactions of third order $A B C$ and $\mathrm{ABD}$ have a positive effect on methanol yield, production and selectivity.

Generally, these results suggest that the use of membrane permeable to water or the presence of $\mathrm{CO}$ in the feed could improve the efficiency of the process with a higher carbon conversion, methanol yield, selectivity and production avoiding the use of recycle that increases the reactor volume and costs or avoiding the operation at a lower temperature that decreases kinetic.

In particular, membrane has a higher effect on carbon conversion and methanol yield while the presence of $\mathrm{CO}$ has a higher effect on methanol production and selectivity.

A mathematical model is developed for the analyzed responses as function of significant factors and interactions, as the following relations (see Equations (9)-(12)):

$$
\text { Conversion } \begin{aligned}
(\%) & =31.09+6.42 \cdot A-16.26 \cdot B-10.56 \cdot C-6.39 \cdot A C+10.91 \cdot D \\
& -5.93 \cdot B D\left(R^{2}=0.9\right)
\end{aligned}
$$




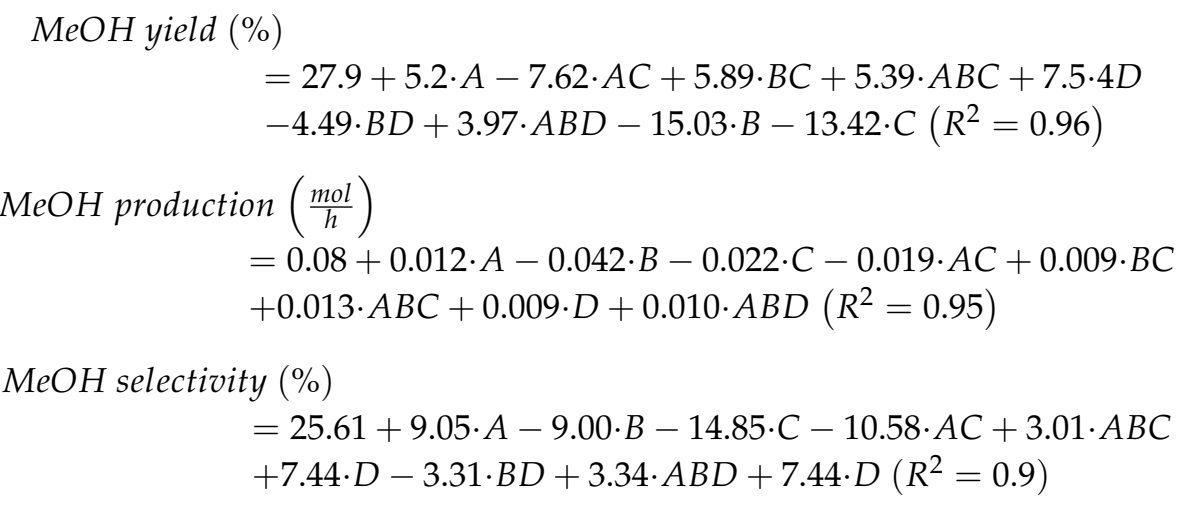

where $\mathrm{A}, \mathrm{B}, \mathrm{C}, \mathrm{D}$ are main factors respectively $\mathrm{CO}$ composition in the feed, temperature, recycle of unconverted gases, and water removal, while $\mathrm{BD}, \mathrm{AC}, \mathrm{BC}$ are the interactions of second order and $\mathrm{ABD}$ and $\mathrm{ABC}$ are the interactions of third order.

The trend of residues in Figure 3 shows that the obtained mathematical models are correct: a good agreement between calculated and simulation data is present. This is also confirmed by the values of $\mathrm{R}^{2}$ : it is closer to unit for all mathematical models.

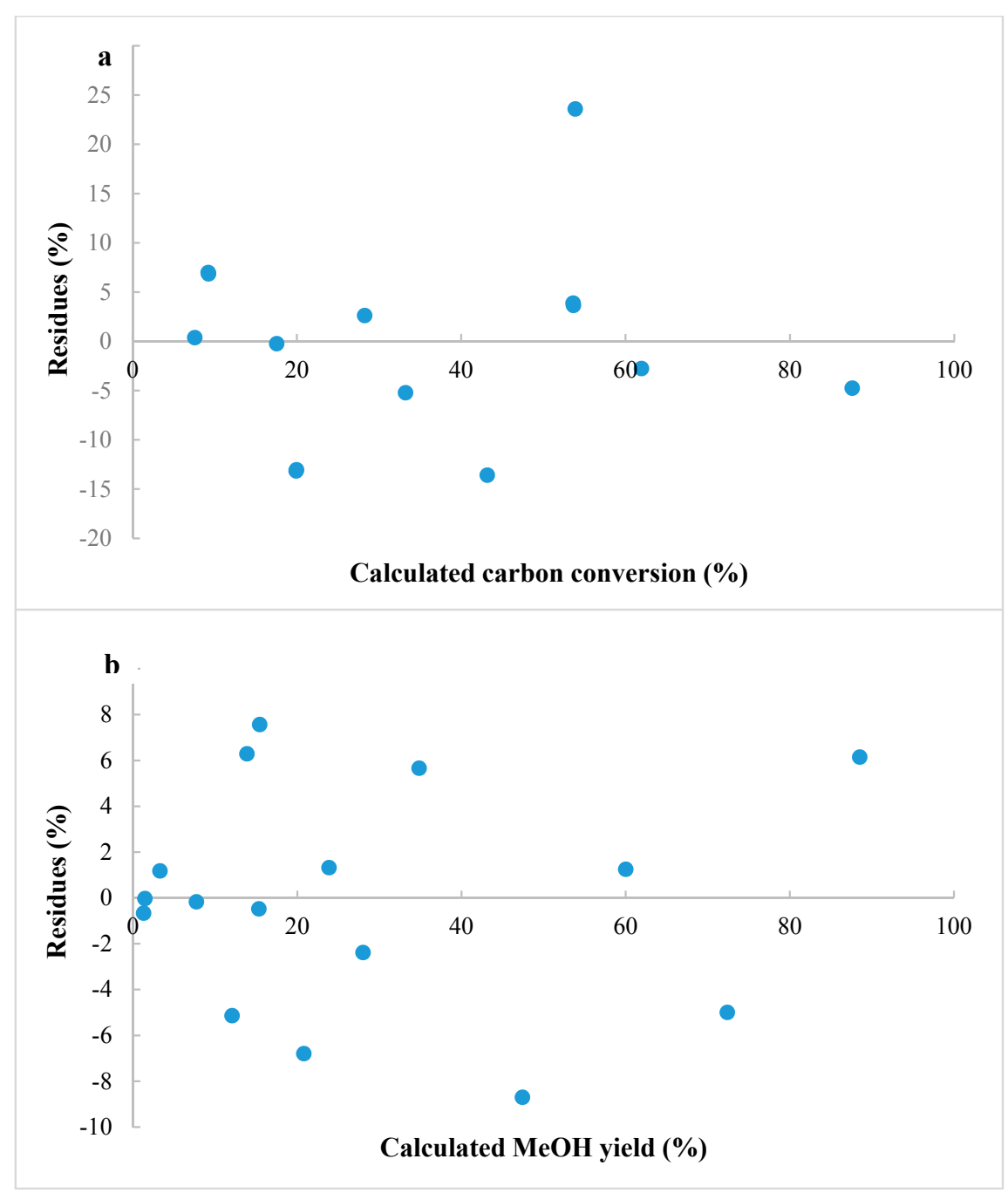

Figure 3. Cont. 


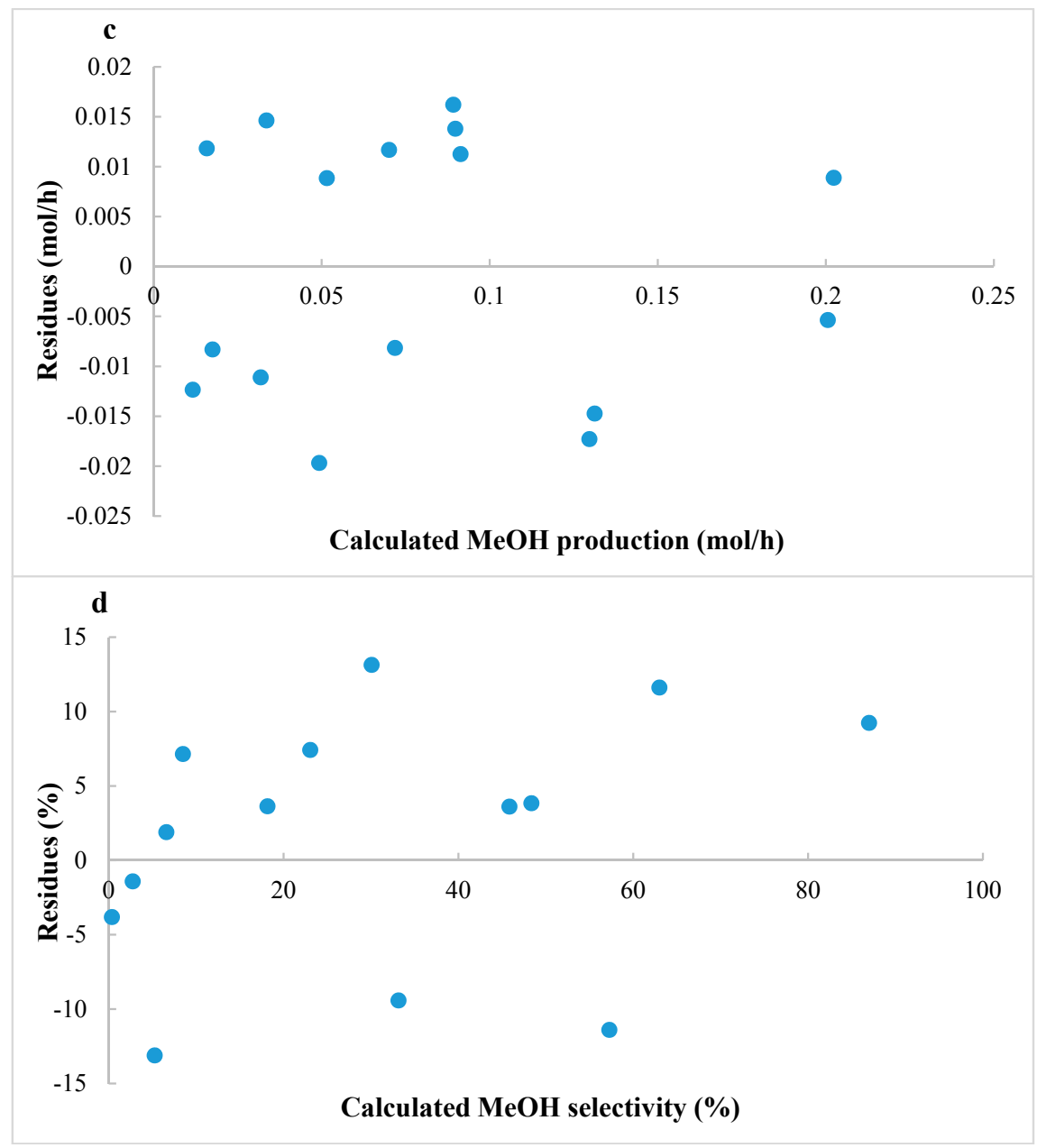

Figure 3. Trend of residues for (a) carbon conversion, (b) methanol yield, (c) methanol production, and (d) methanol selectivity.

An accurate analysis is also developed for interaction factors with the test of two levels. Figure 4 shows the analysis of interaction AC and BD for carbon conversion. Results show that at a higher level of factor $\mathrm{A}$, it is possible to improve carbon conversion to methanol by operating with factor $C$ at a lower level, then without recycle. A higher value of conversion can be obtained with factor $\mathrm{D}$ at a higher level and factor $\mathrm{B}$ at a lower level.

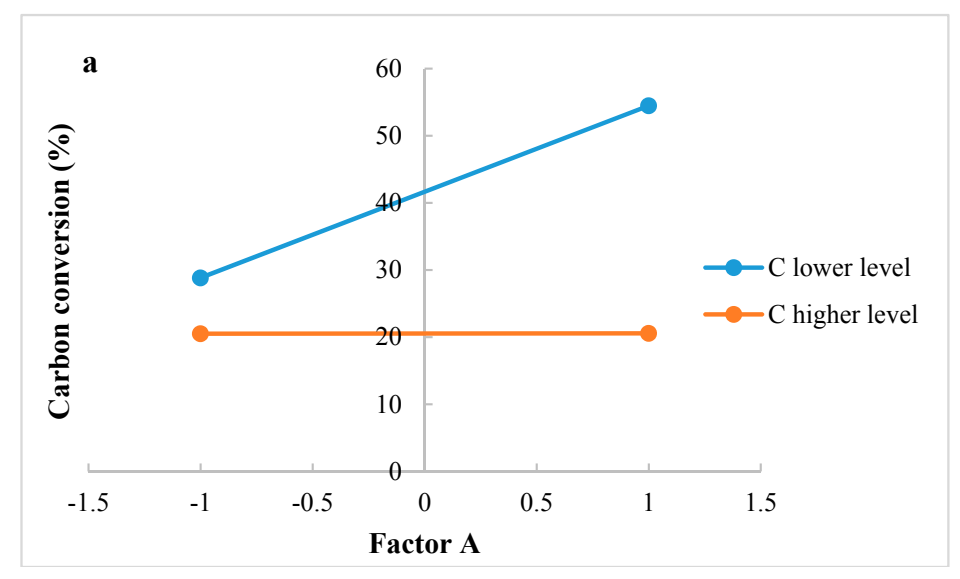

Figure 4. Cont. 


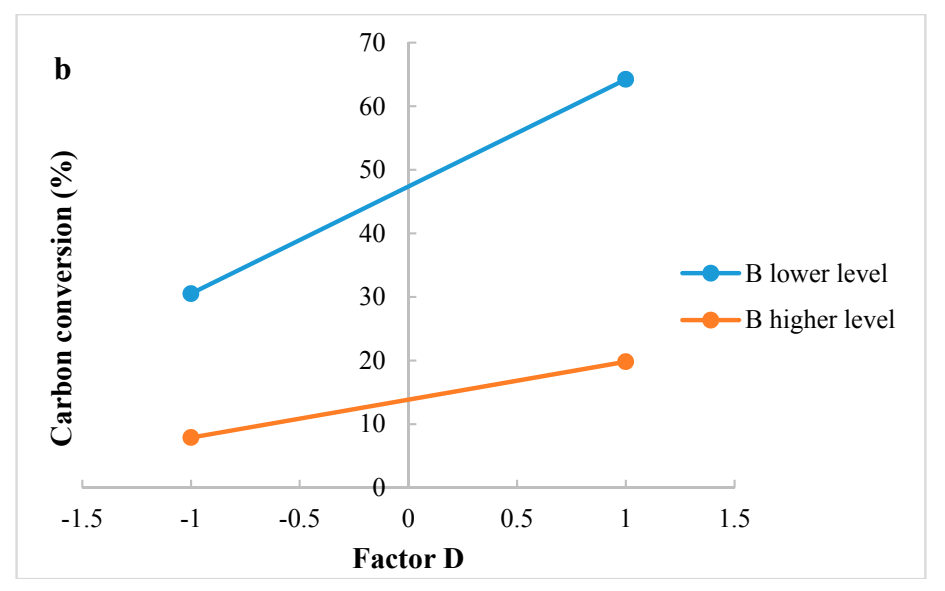

Figure 4. (a) Test of two levels for the analysis of interaction AC in carbon conversion; (b) Test of two levels for the analysis of interaction BD in carbon conversion. (A = CO composition in $\mathrm{mol} \%$, $\mathrm{B}=$ temperature in ${ }^{\circ} \mathrm{C}, \mathrm{C}=$ recycle in $\%, \mathrm{D}=$ water removal in $\%$ ).

Figure 5 shows the test of two levels for interactions AC, BC, BD, that are significant for methanol yield.

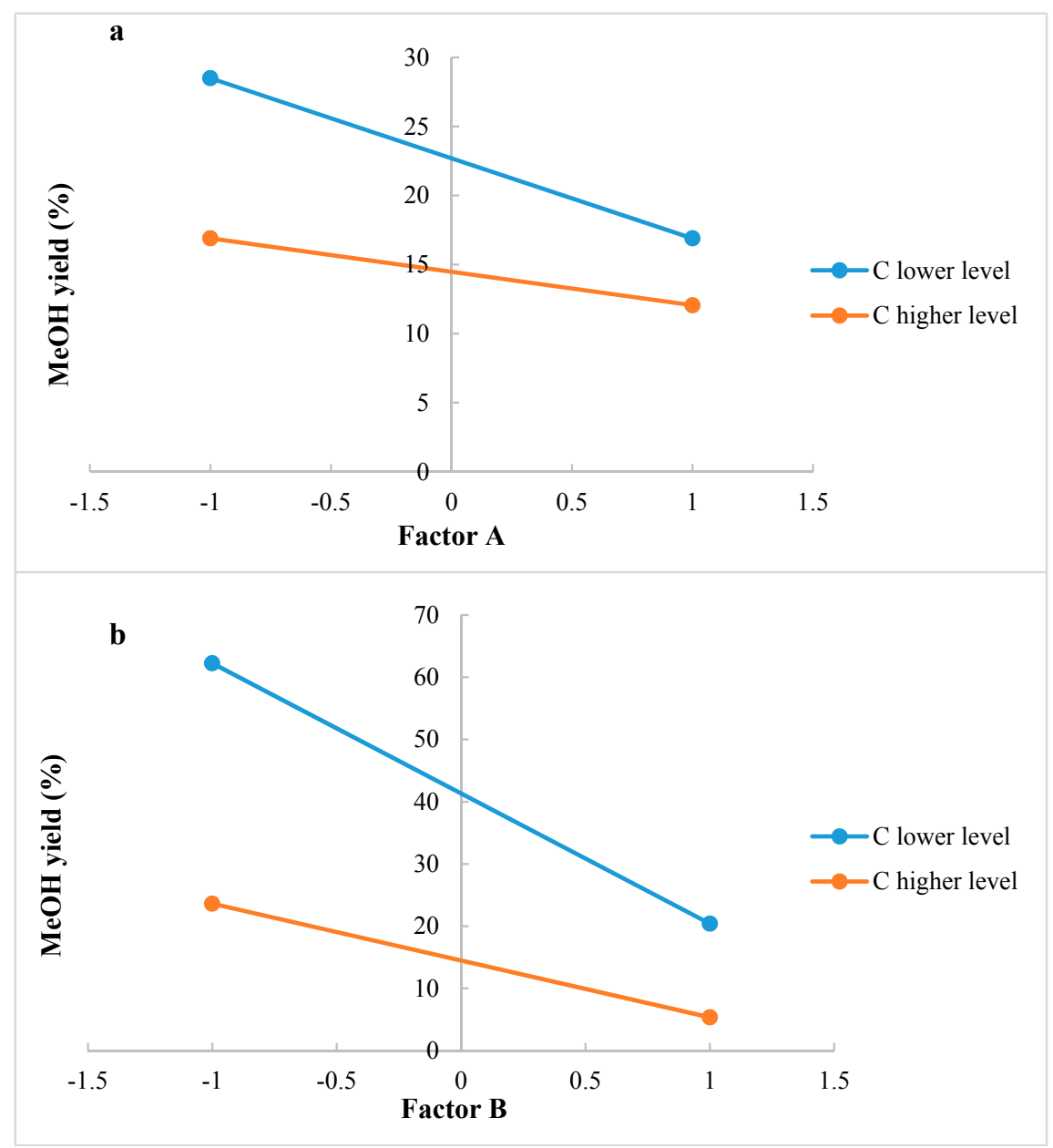

Figure 5. Cont. 


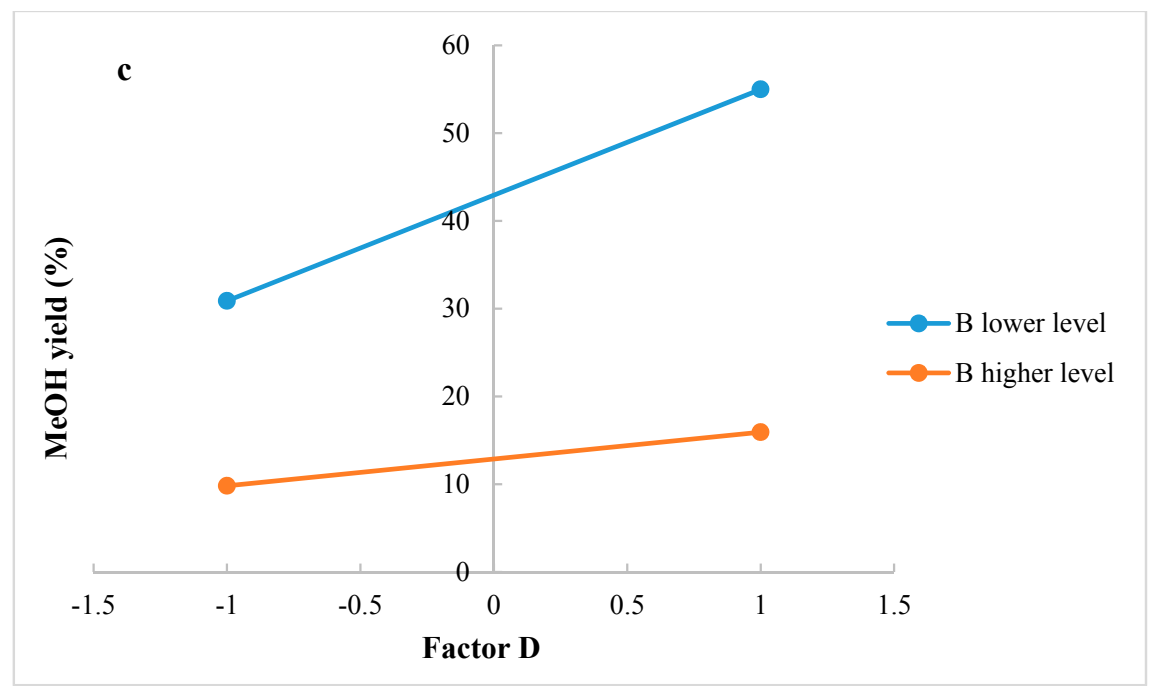

Figure 5. (a) Test of two levels for the analysis of interaction AC in methanol yield; (b) Test of two levels for the analysis of interaction $\mathrm{BC}$ in methanol yield (c) Test of two levels for the analysis of interaction $\mathrm{BD}$ in methanol yield. ( $\mathrm{A}=\mathrm{CO}$ composition in $\mathrm{mol} \%, \mathrm{~B}=$ temperature in ${ }^{\circ} \mathrm{C}, \mathrm{C}=$ recycle in $\%, \mathrm{D}=$ water removal in \%).

With factor $\mathrm{A}$ at a lower level, a higher methanol yield is obtained with factor $\mathrm{C}$ at a lower level. However, in these conditions, a lower carbon conversion is obtained. Factor $\mathrm{B}$ and $\mathrm{C}$ at a lower level in interaction $\mathrm{BC}$ allows to have a higher methanol yield. In interaction $\mathrm{BD}$, factor $\mathrm{B}$ and $\mathrm{D}$ must to be at a lower and higher level, respectively, to have a higher methanol yield: carbon conversion is also higher.

Figure 6 shows the test of two levels for interactions $A C$ and $B C$ in methanol production. Methanol production is higher at lower level of factor A and C in interaction AC. Factor B and C at a lower level ensure to have a higher methanol production. These conditions in interaction $\mathrm{BC}$ allow for also to have a higher methanol yield.

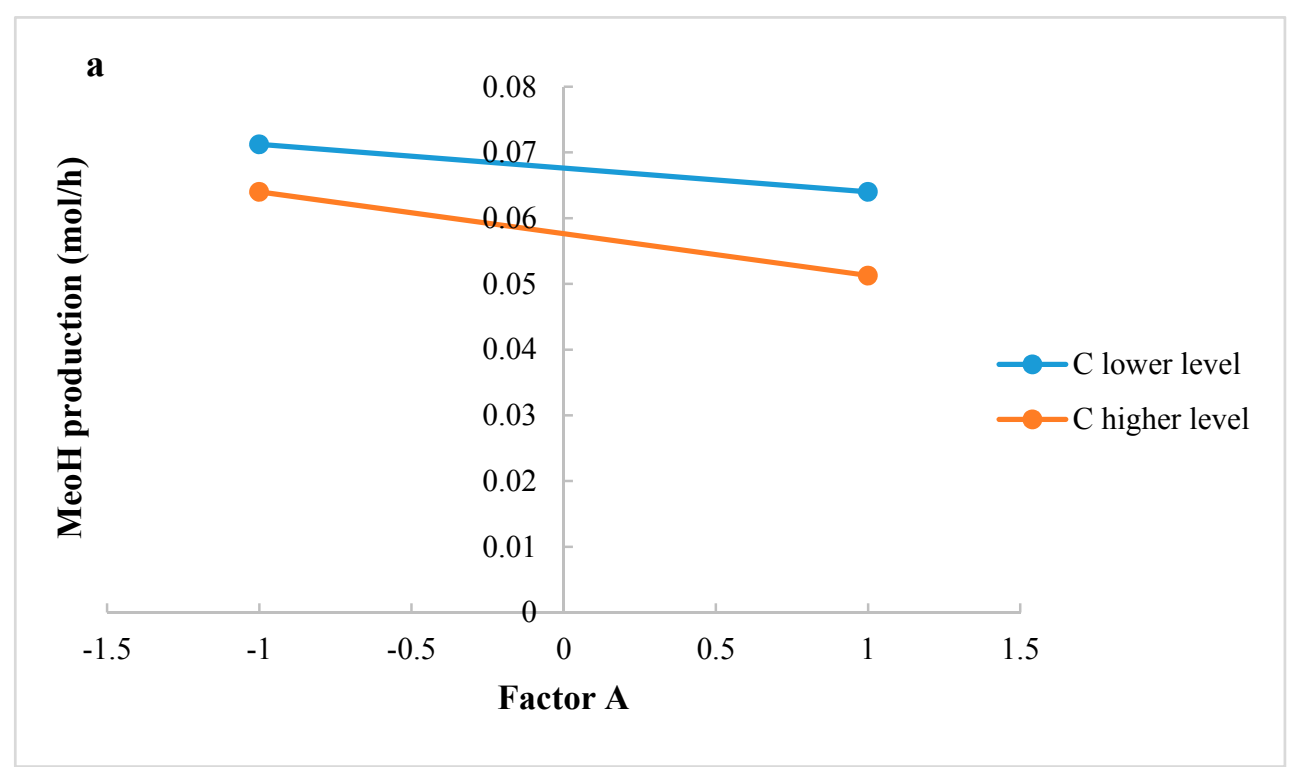

Figure 6. Cont. 


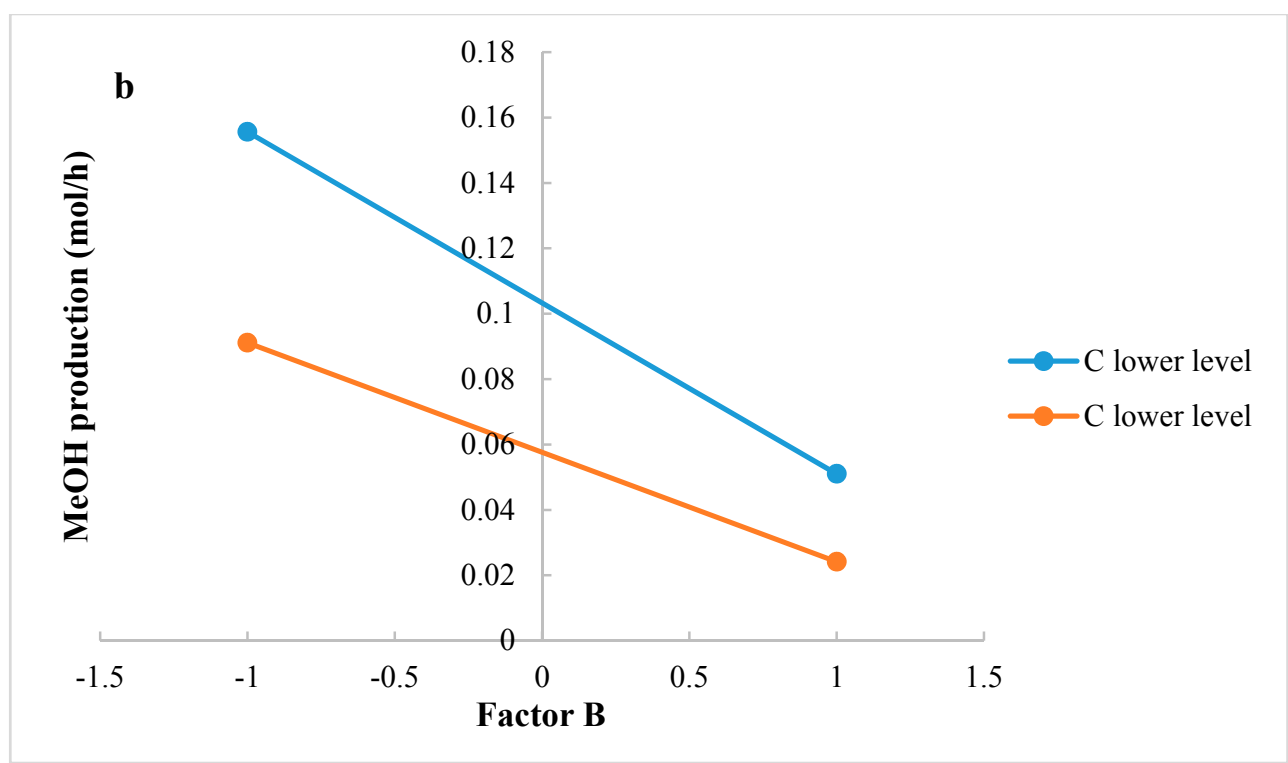

Figure 6. (a) Test of two levels for the analysis of interaction AC in methanol production; (b) Test of two levels for the analysis of interaction $\mathrm{BC}$ in methanol production (A = CO composition in $\mathrm{mol} \%$, $\mathrm{B}=$ temperature in ${ }^{\circ} \mathrm{C}, \mathrm{C}=$ recycle in $\%, \mathrm{D}=$ water removal in $\%$ ).

Figure 7 shows an analysis of significant interaction AC and BD for methanol selectivity. As for carbon conversion, for interaction $\mathrm{AC}$ a higher selectivity is obtained with factor A at a higher level and factor $\mathrm{C}$ at a lower level. In interaction $\mathrm{DB}$, factor $\mathrm{D}$ and $\mathrm{B}$ at a lower level ensures a higher methanol selectivity.

The analysis of two levels suggests that a common interaction that ensures a higher efficiency for all analyzed responses is not present. In order to optimize the process, it is preferable to consider the main factors, in particular the addition of $\mathrm{CO}$ to pure $\mathrm{CO}_{2}$ in the feed or the use of membrane permeable to water.

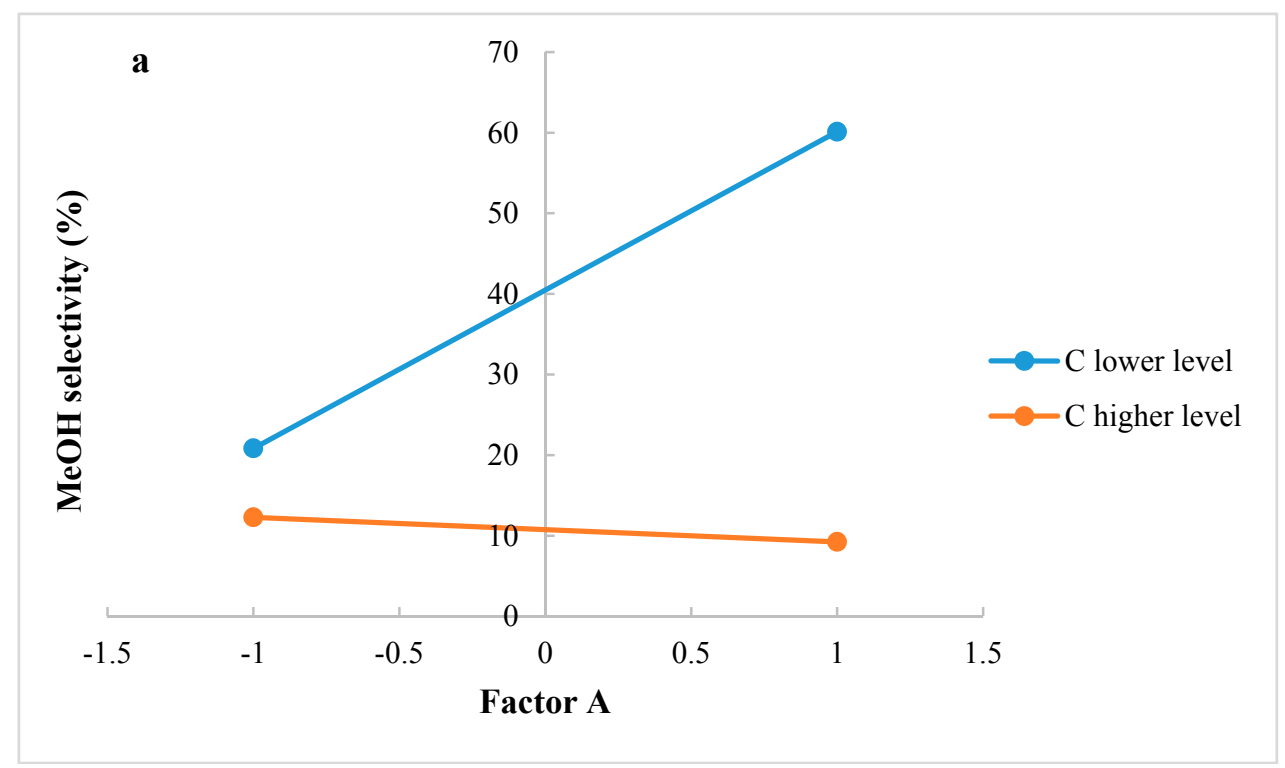

Figure 7. Cont. 


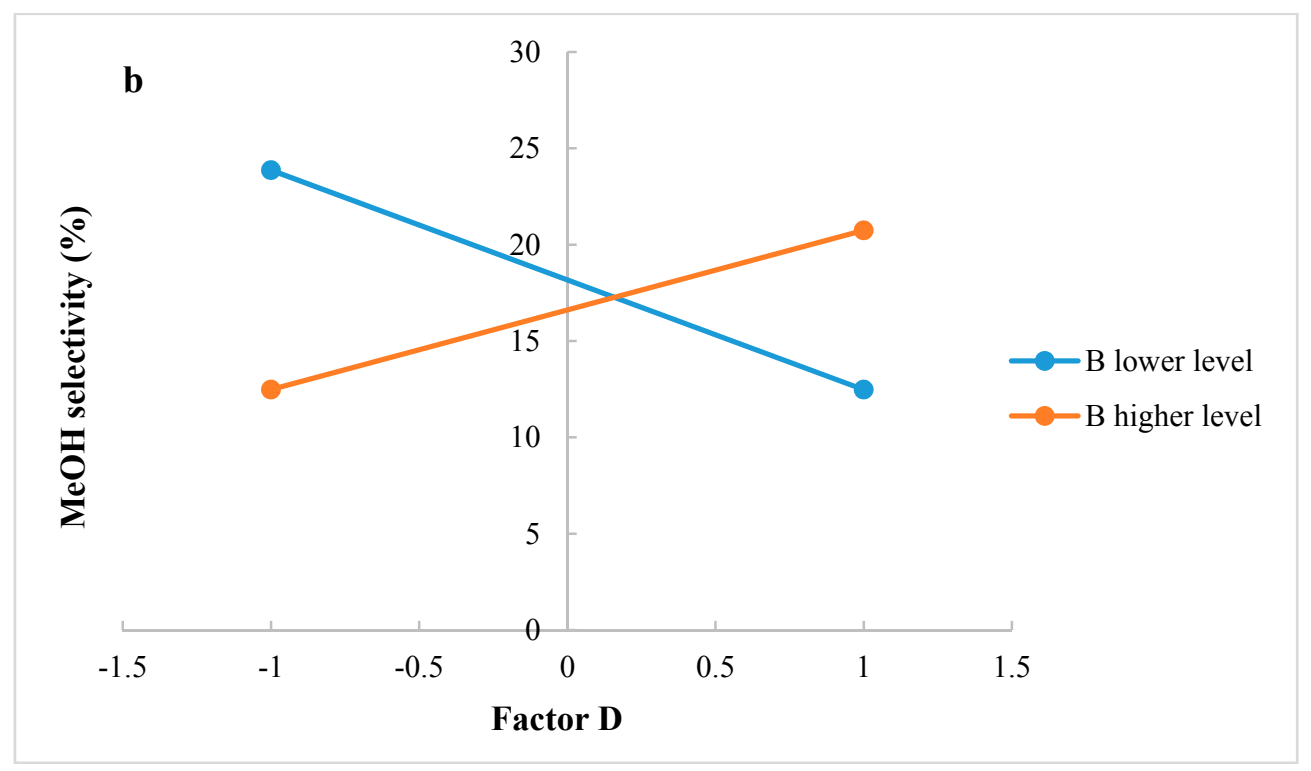

Figure 7. (a) Test of two levels for the analysis of interaction AC in methanol selectivity; (b) Test of two levels for the analysis of interaction $\mathrm{BD}$ in methanol selectivity ( $\mathrm{A}=\mathrm{CO}$ composition in $\mathrm{mol} \%$, $\mathrm{B}=$ temperature in ${ }^{\circ} \mathrm{C}, \mathrm{C}=$ recycle in $\%, \mathrm{D}=$ water removal in $\%$ ).

\subsection{Results of Response Surface Methodology}

Table 4 shows the chosen factors and the values of their levels set in a face centered composite central design, used to find the response surface plot of the responses analyzed in ANOVA analysis. Factors are the same used in previous ANOVA analysis: CO concentration in the feed, temperature, the recycle of unconverted gas and the removal of water through a membrane. An analysis of three levels is developed for each factors.

Table 4. Factors and values of their levels chosen in CCD analysis.

\begin{tabular}{ccccc}
\hline \multirow{2}{*}{ Code } & Factor & \multicolumn{3}{c}{ Level } \\
\cline { 3 - 5 } & & $\mathbf{( - )}$ & $\mathbf{( 0 )}$ & $\mathbf{( + )}$ \\
\hline $\mathrm{A}$ & CO concentration in the feed $(\mathrm{mol} \%)$ & 0 & 10 & 20 \\
$\mathrm{~B}$ & Temperature $\left({ }^{\circ} \mathrm{C}\right)$ & 200 & 240 & 280 \\
$\mathrm{C}$ & Recycle $(\%)$ & 0 & 45 & 90 \\
$\mathrm{D}$ & Water removal $(\%)$ & 0 & 40 & 80 \\
\hline
\end{tabular}

Figure 8 shows the response surface plot of carbon conversion: it is possible to have a conversion higher than $60 \%$ using a membrane reactor at single pass with a removal of water equal to $40 \%$ and a CO composition in the feed equal to $10 \%$ (Figure $8 \mathrm{D}$ ). In this case, temperature can be lower, improving kinetic. The same conversion can be obtained also in other cases with membrane reactor and recycle of gases. However, this determines a reactor with greater sizes, increasing its costs, so they are not the better solutions. Then, among all better solutions a membrane reactor at single pass is chosen because it allows to decrease the costs. A carbon conversion higher than $60 \%$ can be obtained also at lower temperature, with CO composition in the feed equal to $20 \%$, with recycle and water removal equal to $40 \%$ in the first case (Figure $8 \mathrm{~A}$ ). In the second case, carbon conversion higher than $60 \%$ can be obtained also in membrane reactor (water removal equal to $80 \%$ ), with recycle, at lower temperature and with CO composition in the feed equal to 10\% (Figure 8E). Figure 8 shows also that in many cases a temperature higher than $240{ }^{\circ} \mathrm{C}$ decreases carbon conversion because kinetic is not favored. In particular, carbon conversions are between $10 \%$ and $30 \%$. 


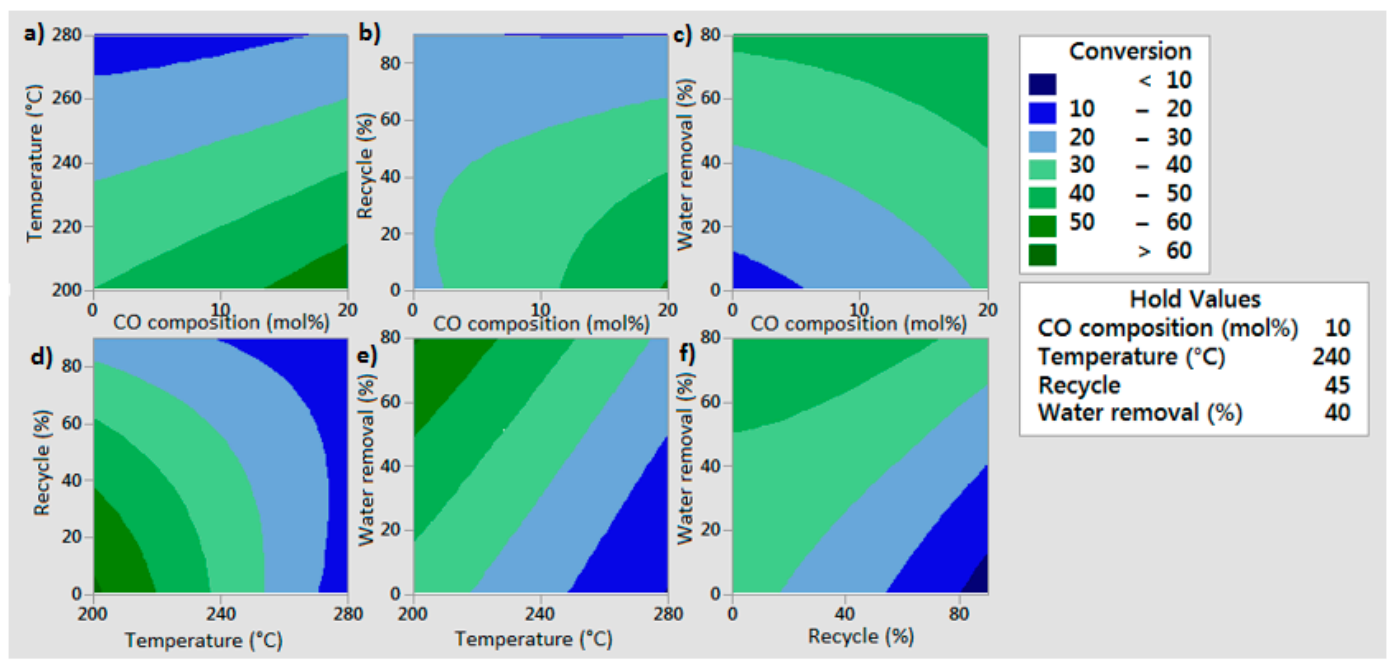

Figure 8. Surface plots of carbon conversion obtained by CCD analysis: (a) carbon conversion as function of temperature and $\mathrm{CO}$ composition in the feed; (b) carbon conversion as function of recycle and $\mathrm{CO}$ composition in the feed; (c) carbon conversion as function of water removal and $\mathrm{CO}$ composition in the feed; (d) carbon conversion as function of recycle and temperature; (e) carbon conversion as function of water removal and temperature; (f) carbon conversion as function of water removal and recycle.

Using a membrane reactor at single pass as in Figure $8 \mathrm{D}$, methanol yield, production, and selectivity are also higher, as shown in Figures 9-11, respectively. A methanol yield higher than $60 \%$, a methanol production higher than $0.15 \mathrm{~mol} / \mathrm{h}$ and a methanol selectivity between $90 \%$ and $95 \%$ can be obtained.

Figure 9 shows that a quite high methanol yield between $50 \%$ and $60 \%$ can be obtained also in membrane reactor with recycle (but increasing costs) in two cases. In the first case, temperature is equal to $200{ }^{\circ} \mathrm{C}, \mathrm{CO}$ composition in the feed is equal to $20 \mathrm{~mol} \%$, recycle is equal to $45 \%$, and water removal is equal to $40 \%$ (Figure $9 \mathrm{~A}$ ). In the second case, temperature is $200{ }^{\circ} \mathrm{C}$, water removal is $80 \%$, CO composition in the feed is equal to $10 \mathrm{~mol} \%$ and recycle is equal to $45 \%$ (Figure 9E).

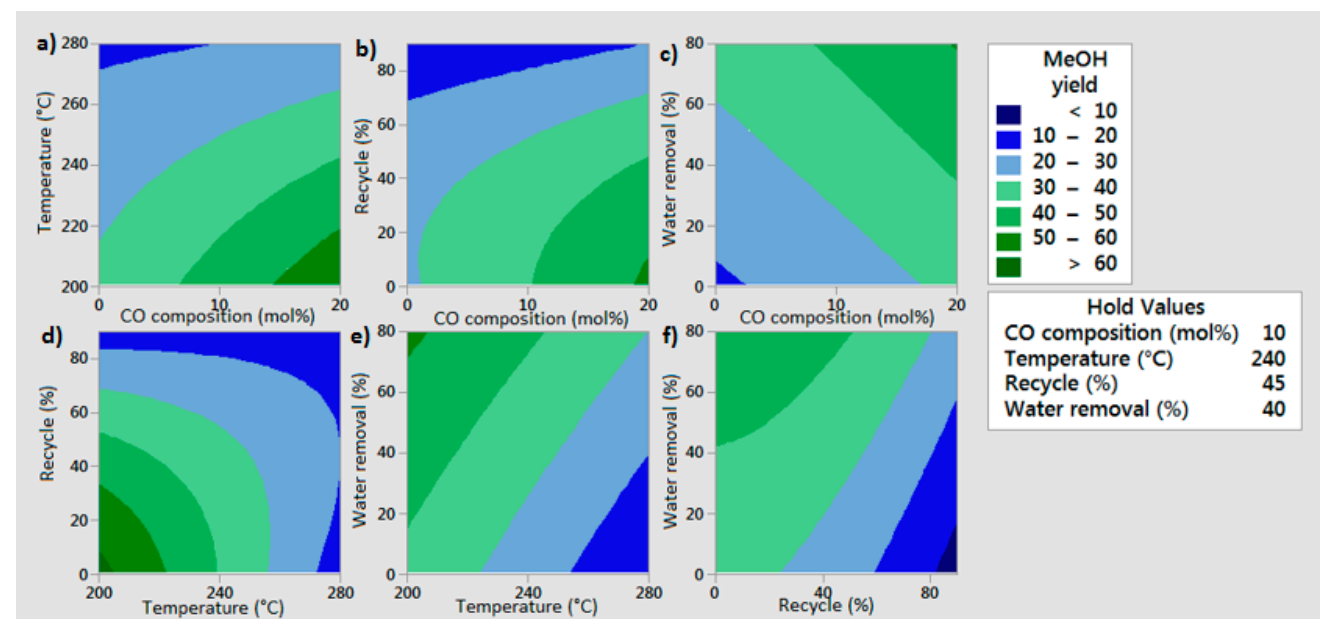

Figure 9. Surface plots of methanol yield obtained by CCD analysis: (a) methanol yield as function of temperature and CO composition in the feed; $(\mathbf{b})$ methanol yield as function of recycle and $\mathrm{CO}$ composition in the feed; (c) methanol yield as function of water removal and CO composition in the feed; (d) methanol yield as function of recycle and temperature; (e) methanol yield as function of water removal and temperature; (f) methanol yield as function of water removal and recycle. 
It is possible to have a methanol yield between $50 \%$ and $60 \%$ also in membrane reactor at single pass with CO composition in the feed equal to $20 \mathrm{~mol} \%$, temperature equal to $240{ }^{\circ} \mathrm{C}$ and water removal equal to $40 \%$ (Figure $9 \mathrm{~B}$ ). However, carbon conversion is between $40 \%$ and $50 \%$. Generally, lower methanol yields are present at lower carbon conversions where higher temperatures are present.

Figure 10 shows that methanol production higher than $0.15 \mathrm{~mol} / \mathrm{h}$ can also be obtained in other conditions that however do not ensure a higher carbon conversion and methanol yield (Figure 10A,E,F) or utilize a reactor with higher costs (Figure 10B,F). Results show that lower methanol productions are clearly and rightly present at lower carbon conversions.

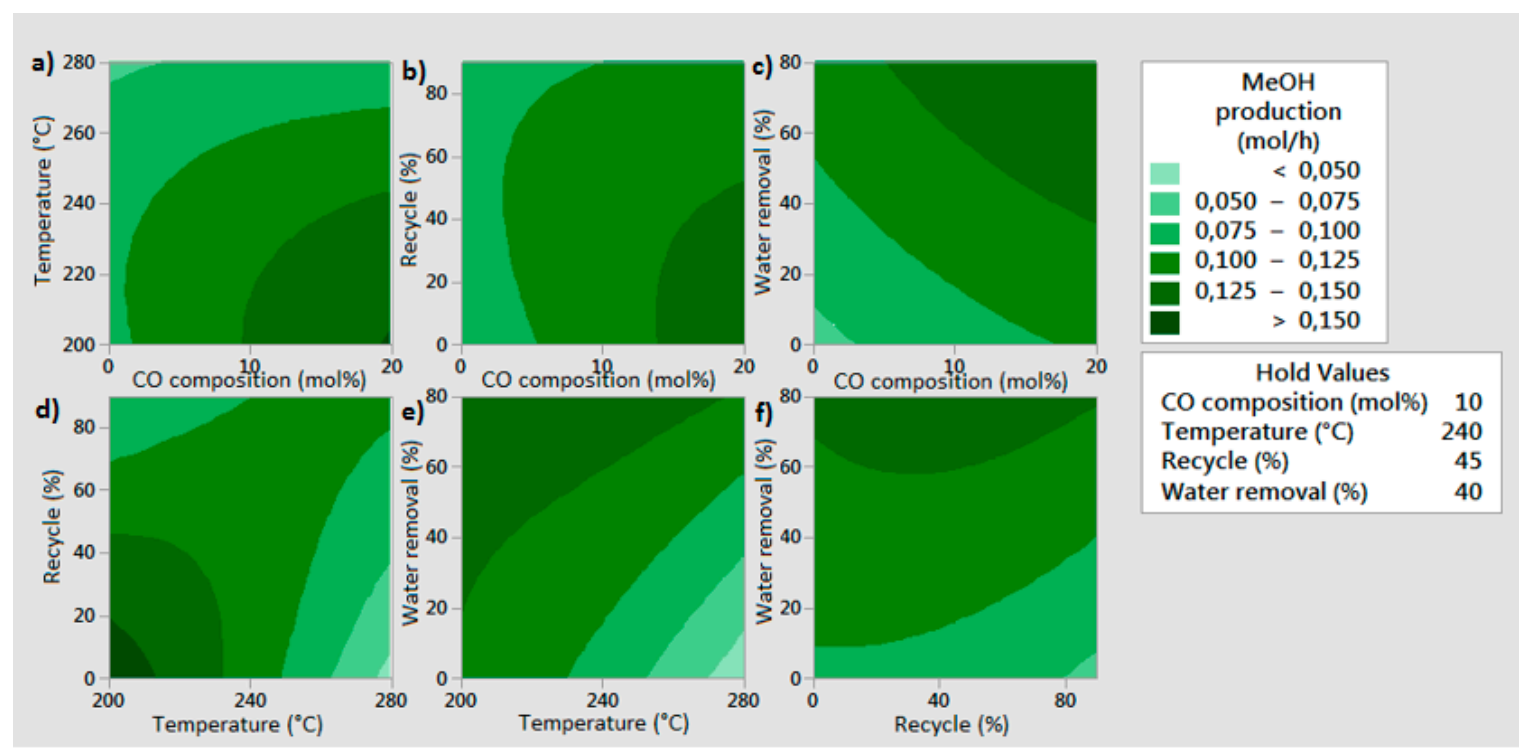

Figure 10. Surface plots of methanol production obtained by CCD analysis: (a) methanol production as function of temperature and $\mathrm{CO}$ composition in the feed; (b) methanol production as function of recycle and $\mathrm{CO}$ composition in the feed; (c) methanol production as function of water removal and $\mathrm{CO}$ composition in the feed; (d) methanol production as function of recycle and temperature; (e) methanol production as function of water removal and temperature; $(\mathbf{f})$ methanol production as function of water removal and recycle.

Figure 11 shows that a methanol selectivity higher than $95 \%$ can be also obtained in two cases (Figure $11 \mathrm{C}, \mathrm{E}$ ), but carbon conversion varies between $10 \%$ and $50 \%$. The first case, Figure 11C, is when CO composition in the feed is $20 \mathrm{~mol} \%$, water removal is $80 \%$, recycle is $45 \%$ and temperature is $240{ }^{\circ} \mathrm{C}$. In this condition, carbon conversion is between $40 \%$ and $50 \%$. The second case, Figure $11 \mathrm{E}$, is when, temperature is $280{ }^{\circ} \mathrm{C}$, recycle $45 \%$, water removal $80 \%$, and CO composition in the feed is $10 \mathrm{~mol} \%$ : carbon conversion is lower and between $10 \%$ and $40 \%$. 

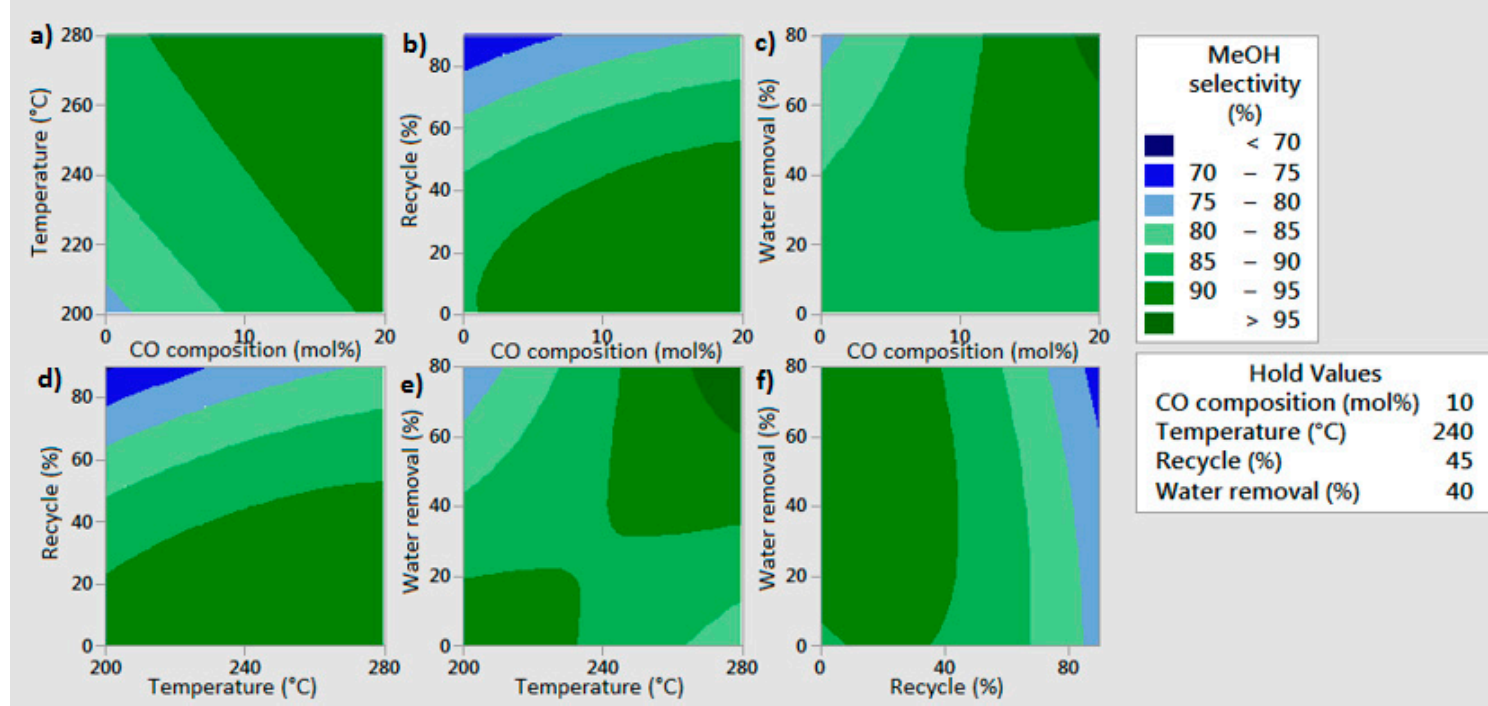

Figure 11. Surface plots of methanol selectivity obtained by CCD analysis: (a) methanol selectivity as function of temperature and CO composition in the feed; (b) methanol selectivity as function of recycle and $\mathrm{CO}$ composition in the feed; (c) methanol selectivity as function of water removal and $\mathrm{CO}$ composition in the feed; (d) methanol selectivity as function of recycle and temperature; (e) methanol selectivity as function of water removal and temperature; (f) methanol selectivity as function of water removal and recycle.

Optimal conditions and reactor configurations are then found to produce methanol by $\mathrm{CO}_{2}$ and $\mathrm{H}_{2}$. These results are in agreement with results found in ANOVA analysis where main factors can ensure a higher efficiency of the process.

Figures 12-15 show the trend of surface plot of carbon conversion, methanol yield, methanol production and methanol selectivity in the space as function of the analyzed factors.

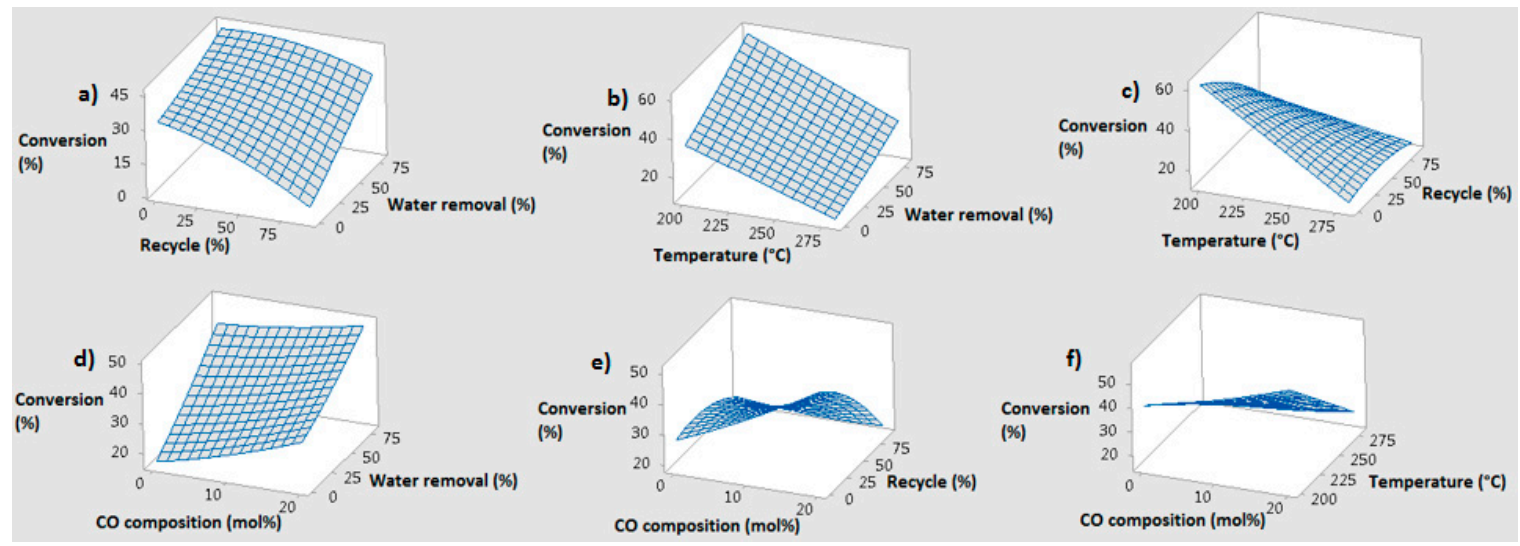

Figure 12. Carbon conversion plots as function of analyzed factors (hold values: recycle $45 \%$, temperature $240{ }^{\circ} \mathrm{C}$, water removal $40 \%$, CO composition in the feed $10 \mathrm{~mol} \%$ ): (a) carbon conversion as function of recycle and water removal; (b) carbon conversion as function of temperature and water removal; (c) carbon conversion as function of temperature and recycle; (d) carbon conversion as function of $\mathrm{CO}$ composition in the feed and water removal; (e) carbon conversion as function of $\mathrm{CO}$ composition in the feed and recycle; $(\mathbf{f})$ carbon conversion as function of CO composition in the feed and temperature. 


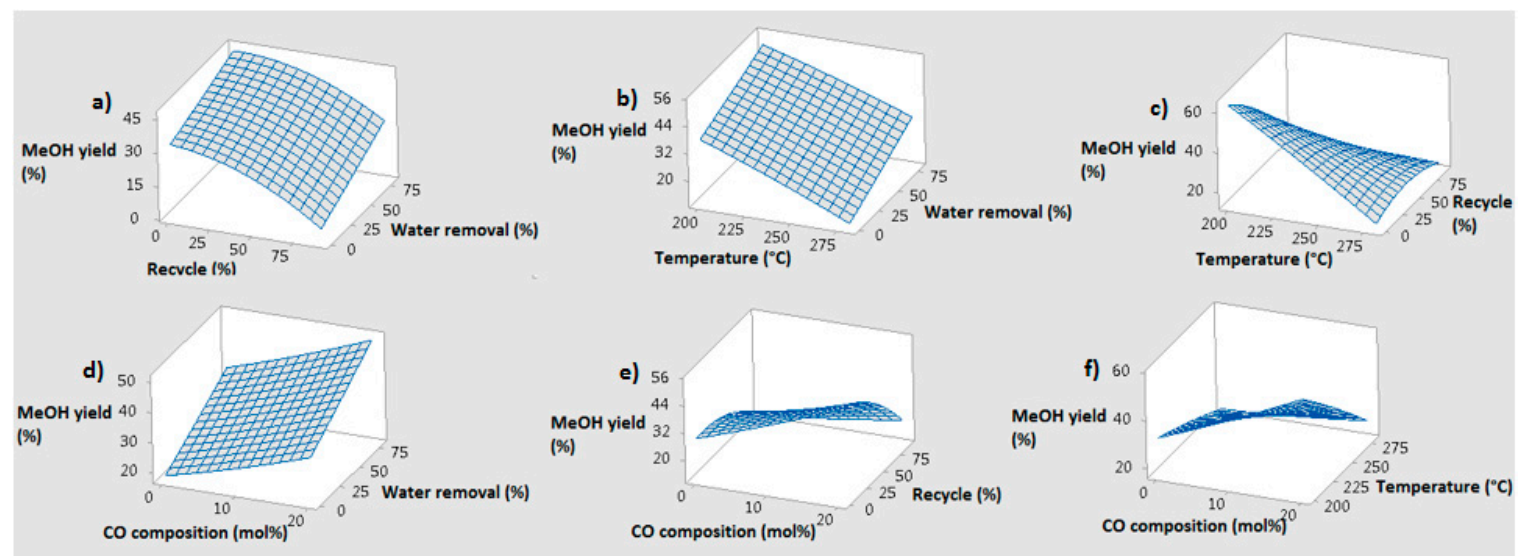

Figure 13. Methanol yield plots as function of analyzed factors (hold values: recycle $45 \%$, temperature $240{ }^{\circ} \mathrm{C}$, water removal $40 \%$, CO composition in the feed $10 \mathrm{~mol} \%$ ): (a) methanol yield as function of recycle and water removal; (b) methanol yield as function of temperature and water removal; (c) methanol yield as function of temperature and recycle; (d) methanol yield as function of $\mathrm{CO}$ composition in the feed and water removal; (e) methanol yield as function of CO composition in the feed and recycle; (f) methanol yield as function of temperature and CO composition in the feed.

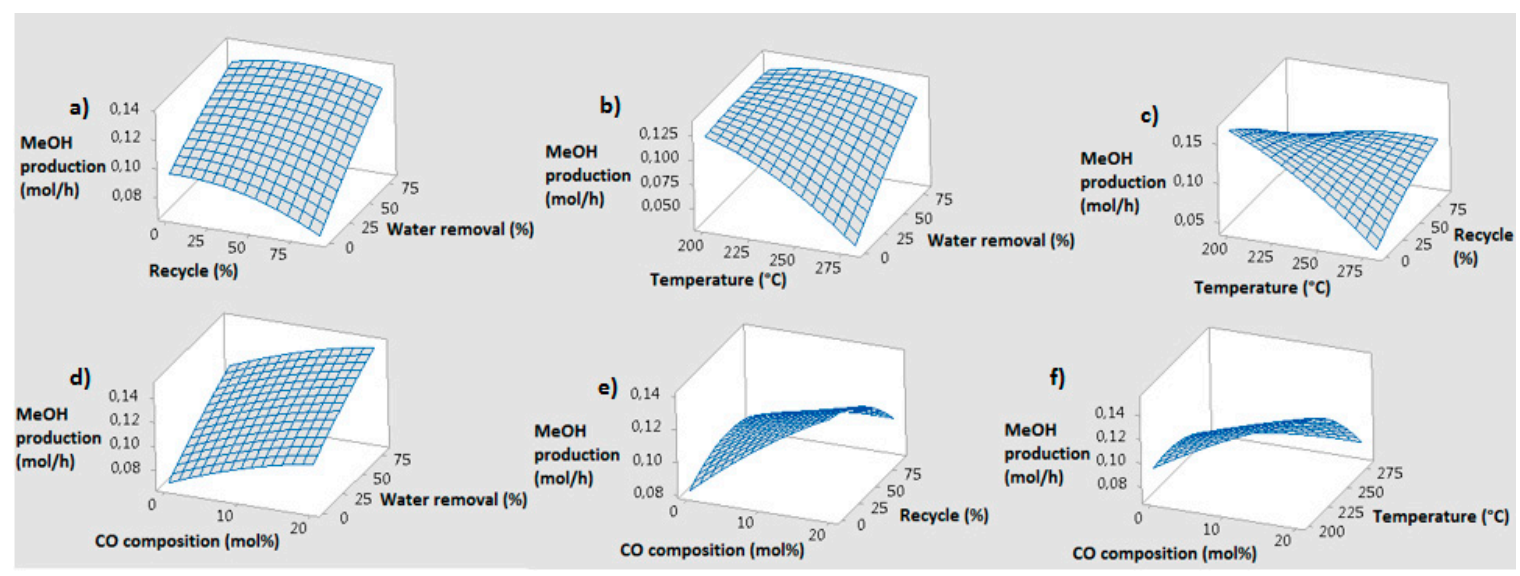

Figure 14. Methanol production surface plots as function of analyzed factors (hold values: recycle $45 \%$, temperature $240{ }^{\circ} \mathrm{C}$, water removal $40 \%$, CO composition in the feed $10 \mathrm{~mol} \%$ ): (a) methanol production as function of recycle and water removal; (b) methanol production as function of temperature and water removal; (c) methanol production as function of temperature and recycle; (d) methanol production as function of $\mathrm{CO}$ composition and water removal; (e) methanol production as function of $\mathrm{CO}$ composition in the feed and recycle; (f) methanol production as function of $\mathrm{CO}$ composition in the feed and temperature. 


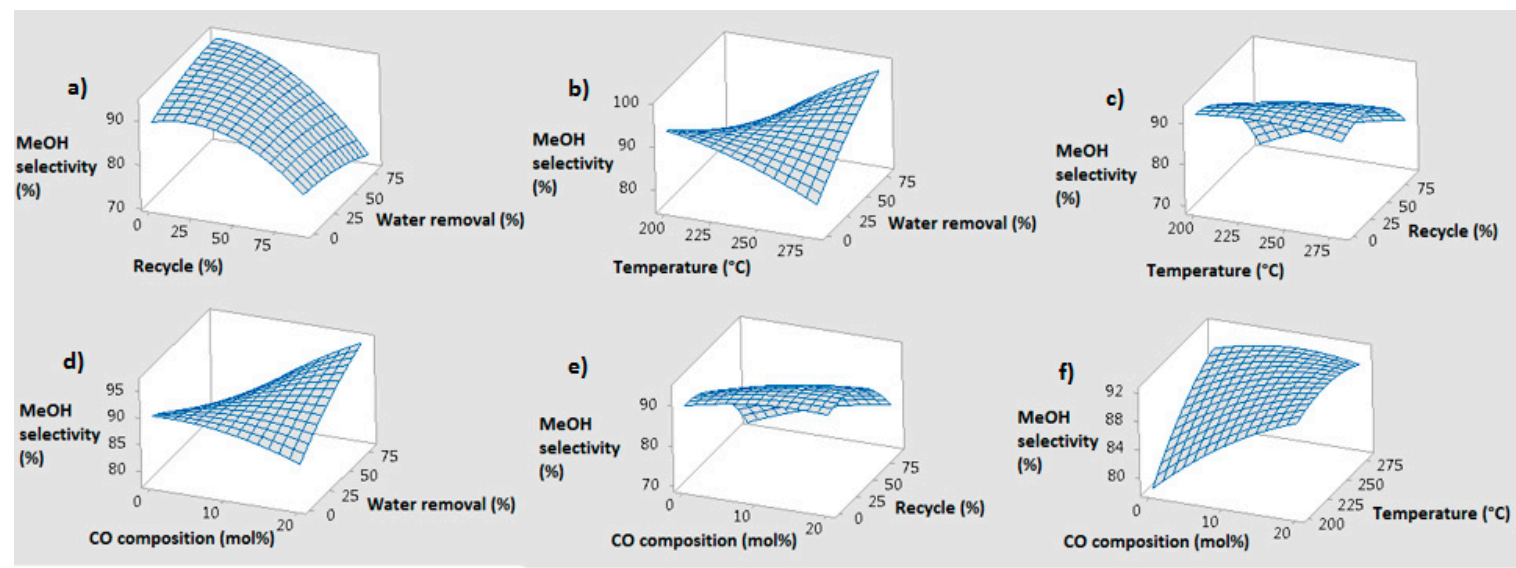

Figure 15. Methanol selectivity surface plots as function of analyzed factors (hold values: recycle $45 \%$, temperature $240{ }^{\circ} \mathrm{C}$, water removal $40 \%$, CO composition in the feed $10 \mathrm{~mol} \%$ ): (a) methanol selectivity as function of recycle and water removal; (b) methanol selectivity as function of temperature and water removal; (c) methanol selectivity as function of temperature and recycle; (d) methanol selectivity as function of $\mathrm{CO}$ composition in the feed and water removal; (e) methanol selectivity as function of $\mathrm{CO}$ composition in the feed and recycle; (f) methanol selectivity as function of temperature and $\mathrm{CO}$ composition in the feed.

The quadratic expressions of these plots are the following (see Equations (13)-(16)):

$$
\begin{aligned}
& \text { Conversion }(\%)=32.55+5.37 \cdot A-14.82 \cdot B-9.26 \cdot C-6.22 \cdot A C+10.86 \cdot D \\
& +8.65 \cdot B C+4.36 \cdot C D \\
& \begin{aligned}
\text { MeOH yield }(\%)= & 32.97+7.63 \cdot A-3.7 \cdot A C+11.71 \cdot B C+8.36 \cdot D-3.7 \cdot A C \\
- & 5.2 \cdot A B-12.12 \cdot B-11.98 \cdot C \\
\text { MeOH production } & \left(\frac{\mathrm{mol}}{\mathrm{h}}\right) \\
& =0.114+0.017 \cdot A-0.023 \cdot B-0.019 \cdot A C+0.022 \cdot D \\
& +0.021 \cdot B D+0.038 \cdot B C
\end{aligned}
\end{aligned}
$$

MeOH selectivity $(\%)=77-0.8 \cdot C+8.42 \cdot B D$

where A, B, C, D are main factors respectively $\mathrm{CO}$ composition in the feed, temperature, recycle and water removal, while $\mathrm{BD}, \mathrm{AC}, \mathrm{BC}$ are the interactions of second order.

A comparison between a membrane reactor with the optimal operating conditions found through the previous response surface methodology and a traditional reactor is developed. The traditional reactor is at $200{ }^{\circ} \mathrm{C}, 40$ bar and the feed in amount of $1 \mathrm{~mol} / \mathrm{h}$ contains $\mathrm{CO}_{2}$ and $\mathrm{H}_{2}$ in stochiometric conditions. Results are reported in Table 5. The advantages of membrane reactor are evident, allowing for a higher conversion, methanol production, and yield. In particular, carbon conversion and methanol yield are respectively increased by $29 \%$ and $34 \%$. In addition, methanol production and hydrogen conversion are higher in membrane reactor, respectively, equal to $0.15 \mathrm{~mol} / \mathrm{h}$ and $49 \%$.

Table 5. Comparison between membrane reactor and traditional reactor for methanol production.

\begin{tabular}{ccc}
\hline Factor & Membrane Reactor & Traditional Reactor \\
\hline Carbon conversion (\%) & 62 & 33 \\
Hydrogen conversion (\%) & 49 & 32 \\
Methanol yield (\%) & 61 & 27 \\
Methanol production & 0.15 & 0.076 \\
(mol/h) & & \\
\hline
\end{tabular}




\section{Conclusions}

The main obstacle to methanol synthesis from $\mathrm{CO}_{2}$ rich streams is thermodynamic. For pure $\mathrm{CO}$, a one pass methanol yield of nearly $55 \%$ can be obtained at $252{ }^{\circ} \mathrm{C}$, while pure $\mathrm{CO}_{2}$ would only yield $18 \%$.

In this research, different strategies to overcome thermodynamic limits in methanol production from pure $\mathrm{CO}_{2}$ and $\mathrm{H}_{2}$ are suggested and analyzed. The addition of $\mathrm{CO}$ to the feed, the operating at lower temperature, the recycle of unconverted gas, and the use of membrane removing water inside the reactor can be applied to have higher efficiencies in methanol production. An ANOVA analysis and a response surface methodology are carried out with the aim to find the best solution. In these analyses, chosen factors are: $\mathrm{CO}$ composition in the feed, operating temperature, the recycle of unconverted gases, and the presence of zeolite membrane permeable to water. The analyzed responses are: carbon conversion, methanol production, methanol yield and methanol selectivity. Results suggest that a higher carbon conversion, methanol yield, selectivity and production are obtained from a mixture of $\mathrm{CO}_{2}$ and $\mathrm{H}_{2}$, adding $10 \mathrm{~mol} \%$ of $\mathrm{CO}$ in the feed, operating at $200{ }^{\circ} \mathrm{C}$, and using a membrane reactor without recycle. In these conditions, when considering a feed flow rate of $1 \mathrm{~mol} / \mathrm{h}$ carbon conversion, methanol yield, selectivity, and production are respectively higher than $60 \%$, higher than $60 \%, 0.15 \mathrm{~mol} / \mathrm{h}$, and between $90 \%$ and $95 \%$. A tradition reactor, operating at $200{ }^{\circ} \mathrm{C}$, with hydrogen and carbon dioxide in stochiometric conditions allows for having a conversion only equal to $33 \%$ and a methanol yield of $27 \%$ : the advantages of optimized systems are evident. In addition, the traditional system produces only $0.076 \mathrm{~mol} / \mathrm{h}$ of methanol, while membrane reactor can produce $0.15 \mathrm{~mol} / \mathrm{h}$ of methanol with a feed flow rate of $1 \mathrm{~mol} / \mathrm{h}$. The feasibility of methanol synthesis from carbon dioxide can be achieved by circumventing the thermodynamic limitations, through innovative reactor design. Future research should evaluate economic considerations about the optimal solution.

Acknowledgments: The author of the study would like to thank the University of L'Aquila for funding this work. Conflicts of Interest: The author declares no conflict of interest.

\section{References}

1. Kung, H.H.; Cheng, W.H. Methanol Production and Use; M. Dekker: New York, NY, USA, 1994.

2. Bansode, A.; Urakawa, A. Towards full one-pass conversion of carbon dioxide to methanol and methanol-derived products. J. Catal. 2014, 309, 66-70. [CrossRef]

3. Olah, G.A. After Oil and gas: Methanol economy. Catal. Lett. 2004, 93, 1-2. [CrossRef]

4. Olah, G.A.; Goeppert, A.; Prakash, G.K.S. Chemical Recycling of Carbon Dioxide to Methanol and Dimethyl Ether: From Greenhouse Gas to Renewable, Environmentally Carbon Neutral Fuels and Synthetic Hydrocarbons. J. Org. Chem. 2009, 74, 487-498. [CrossRef] [PubMed]

5. Sunggyu, L. Handbook of Alternative Fuel Technologies; CRC Press: New York, NY, USA, 2007; pp. $297-321$.

6. Jadhav, S.G.; Vaidya, P.D.; Bhanage, B.M.; Joshi, J.B. Catalytic carbon dioxide hydrogenation to methanol: A review of recent studies. Chem. Eng. Res. Design 2014, 92, 2557-2567. [CrossRef]

7. Olah, G.A.; Prakash, G.K.S.; Goeppert, A. Anthropogenic Chemical Carbon Cycle for a Sustainable Future. J. Am. Chem. Soc. 2011, 133, 12881-12898. [CrossRef] [PubMed]

8. Pontzen, F.; Liebner, W.; Gronemann, V.; Rothemel, M.; Ahlers, B. CO $\mathrm{C}_{2}$-Based Methanol and DME-Efficient Technologies for Industrial Scale Production. Catal. Today 2011, 171, 242-250. [CrossRef]

9. Arakawa, H. Research and development of on new synthetic routes for basic chemicals by catalytic hydrogenation of $\mathrm{CO}_{2}$. Stud. Surf. Sci. Catal. 1998, 114, 19-30.

10. Zachopoulos, A.; Heracleous, E. Overcoming the equilibrium barriers of $\mathrm{CO}_{2}$ hydrogenation to methanol via water sorption: A thermodynamic analysis. J. CO 2 Util. 2017, 21, 360-367. [CrossRef]

11. Saito, M.; Fujitani, T.; Takeuchi, M.; Watanabe, T. Development of copper/zinc oxide based multicomponent catalyst for methanol synthesis from carbon dioxide and hydrogen. Appl. Catal. A 1996, 138, 311-318. [CrossRef]

12. Reubroycharoen, P.; Vitidsant, T.; Asamic, K.; Yoneyama, Y.; Tsubaki, N. Accelerated methanol synthesis in catalytically active supercritical fluid. Catal. Commun. 2003, 4, 461-464. [CrossRef] 
13. Westerterp, K.R.; Kuczynski, M.; Bodewes, T.N.; Vrijland, M.S.A. Neue Konvertersysteme für die Methanol-Synthese. Chemie Ingenieur Technik 1989, 61, 193-199. [CrossRef]

14. Haut, B.; Halloin, V.; Amor, H.B. Development and analysis of a multi- functional reactor for equilibrium reactions: Benzene hydrogenation and methanol synthesis. Chem. Eng. Process. 2004, 43, 979-986. [CrossRef]

15. Van Bennekom, J.G.; Venderbosch, R.H.; Winkelman, J.G.M.; Wilbers, E.; Assink, D.; Lemmens, K.P.J.; Heeres, H.J. Methanol synthesis beyond chemical equilibrium. Chem. Eng. Sci. 2013, 87, 204-208. [CrossRef]

16. Gallucci, F.; Basile, A. A theoretical analysis of methanol synthesis from $\mathrm{CO}_{2}$ and $\mathrm{H}_{2}$ in a ceramic membrane reactor. Int. J. Hydrog. Energy 2007, 32, 5050-5058. [CrossRef]

17. Struis, R.P.W.J.; Stucki, S.; Wiedorn, M. A membrane reactor for methanol synthesis. J. Membr. Sci. 1996, 113, 93-100. [CrossRef]

18. Struis, R.P.W.J.; Stucki, S. Verification of the membrane reactor for methanol synthesis. Appl. Catal. A Gen. 2001, 216, 117-129. [CrossRef]

19. Chen, G.; Yuan, Q. Methanol synthesis from $\mathrm{CO}_{2}$ using a silicone rubber/ceramic composite membrane reactor. Sep. Purif. Technol. 2004, 34, 227-237. [CrossRef]

20. Barbieri, G.; Marigliano, G.; Golemme, G.; Drioli, E. Simulation of $\mathrm{CO}_{2}$ hydrogenation with $\mathrm{CH}_{3} \mathrm{OH}$ removal in zeolite membrane reactor. Chem. Eng. J. 2002, 85, 53-59. [CrossRef]

21. Gallucci, F.; Paturzo, L.; Basile, A. An experimental study of $\mathrm{CO}_{2}$ hydrogenation into methanol involving a zeolite membrane reactor. Chem. Eng. Proc. 2004, 43, 1029-1033. [CrossRef]

22. Kunkes, E.; Behrens, M. Methanol Chemistry. Available online: http://pubman.mpdl.mpg.de/pubman/ item/escidoc:1587235/component/escidoc:1719633/Methanol\%20Chemistry\%20final.pdf (accessed on 2 February 2018).

23. Sahibzada, M.; Metcalfe, I.S.; Chadwick, D. Methanol synthesis from $\mathrm{CO} / \mathrm{CO}_{2} / \mathrm{H}_{2}$ over $\mathrm{Cu} / \mathrm{ZnO} / \mathrm{Al}_{2} \mathrm{O}_{3}$ at differential and finite conversions. J. Catal. 1998, 174, 111-118. [CrossRef]

24. Van den Bussche, K.M.; Froment, G.F. A steady state kinetic model for methanol synthesis and the water gas shith reaction on commercial $\mathrm{Cu} / \mathrm{ZnO} / \mathrm{Al}_{2} \mathrm{O}_{3}$ catalyst. J. Catal. 1996, 161, 1-10. [CrossRef]

25. Lee, J.S.; Lee, K.H.; Lee, S.Y.; Kim, Y.G. A Comparative-Study of Methanol Synthesis from $\mathrm{CO}_{2} / \mathrm{H}_{2}$ and $\mathrm{CO} / \mathrm{H}_{2}$ over a Cu/ZnO/ $\mathrm{Al}_{2} \mathrm{O}_{3}$ Catalyst. J. Catal. 1993, 144, 414-424. [CrossRef]

26. Montebelli, A.; Visconti, C.G.; Groppi, G.; Tronconi, E.; Ferreira, C.; Kohler, S. Enabling small-scale methanol synthesis reactor through the adoption of high conductive structured catalyst. Catal. Today 2013, 215, 176-185. [CrossRef]

27. Hansen, J.B.; Nielsen, P.E.H. Methanol Synthesis. In Handbook of Heterogenous Catalysis; Ert, G., Knötzinger, H., Weitkamp, J., Eds.; Weily-VCH: New York, NY, USA, 2008.

28. Montgomery, D.C. Design and Analysis of Experiments; John Wiley \& Sons: New York, NY, USA, 2005.

29. Dutka, B.M.; Ditaranto, M.; Løvås, T. Application of a Central Composite Design for the Study of $\mathrm{NO}_{x}$ Emission Performance of a Low $\mathrm{NO}_{x}$ Burner. Energies 2015, 8, 3606-3627. [CrossRef]

30. Box, G.E.P.; Hunter, J.S.; Hunter, W.G. Statistics for Experimenters: Design, Innovation, and Discovery; Wiley-Interscience: Hoboken, NJ, USA, 2005; pp. 447-455.

31. Cheng, T.; Rousseau, R.W.; Kliopatric, P.K. Methanol synthesis reactions: Calculations of equilibrium conversions using equations of state. Ind. Eng. Chem. Process Des. Dev. 1986, 25, 477-481. [CrossRef]

32. Skrzypek, J.; Lachowska, M.; Grzesik, M.; Słoczyński, J.; Nowak, P. Thermodynamics and kinetics of low pressure methanol synthesis. Chem. Eng. J. 1995, 58, 101-108. [CrossRef]

33. An, X.; Zuo, Y.; Zhang, Q.; Wang, J. Methanol synthesis from $\mathrm{CO}_{2}$ hydrogenation with a $\mathrm{Cu} / \mathrm{Zn} / \mathrm{Al} / \mathrm{Zr}$ fibrous catalyst. Chin. J. Chem. Eng. 2009, 17, 88-94. [CrossRef]

34. Manenti, F.; Cieri, S.; Restelli, M. Considerations on the steady state modeling of methanol synthesis fixed bed reactor. Chem. Eng. Sci. 2011, 86, 152-162. [CrossRef]

(C) 2018 by the author. Licensee MDPI, Basel, Switzerland. This article is an open access article distributed under the terms and conditions of the Creative Commons Attribution (CC BY) license (http://creativecommons.org/licenses/by/4.0/). 